\title{
Caffeine and Exercise: What Next?
}

\author{
Craig Pickering ${ }^{1,2}\left[\right.$. Jozo Grgic ${ }^{3}$
}

Published online: 11 April 2019

(c) The Author(s) 2019

\begin{abstract}
Caffeine is a widely utilized performance-enhancing supplement used by athletes and non-athletes alike. In recent years, a number of meta-analyses have demonstrated that caffeine's ergogenic effects on exercise performance are well-established and well-replicated, appearing consistent across a broad range of exercise modalities. As such, it is clear that caffeine is an ergogenic aid—but can we further explore the context of this ergogenic aid in order to better inform practice? We propose that future research should aim to better understand the nuances of caffeine use within sport and exercise. Here, we propose a number of areas for exploration within future caffeine research. These include an understanding of the effects of training status, habitual caffeine use, time of day, age, and sex on caffeine ergogenicity, as well as further insight into the modifying effects of genotype. We also propose that a better understanding of the wider, non-direct effects of caffeine on exercise, such as how it modifies sleep, anxiety, and post-exercise recovery, will ensure athletes can maximize the performance benefits of caffeine supplementation during both training and competition. Whilst not exhaustive, we hope that the questions provided within this manuscript will prompt researchers to explore areas with the potential to have a large impact on caffeine use in the future.
\end{abstract}

\section{Key Points}

Caffeine is a well-replicated performance-enhancing supplement, with these effects established at metaanalysis level; as such, further research exploring the straightforward ergogenic effects of caffeine is unlikely to alter practice.

However, there are many unanswered questions with regard to the use of caffeine in sport which represent promising avenues to enhance our understanding and provide some nuance into the use of caffeine around exercise.

These unanswered questions include whether the ergogenic effects of caffeine alter with sex, time of day, genotype, habitual use, and training status, and there is a need for a greater understanding of the effects of caffeine on performance anxiety and post-exercise recovery.

Craig Pickering

craig@dnafit.com

1 Institute of Coaching and Performance, School of Sport and Wellbeing, University of Central Lancashire, Fylde Road, Preston PR1 2HE, UK

2 The Prenetics DNAFit Research Centre, London, UK

3 Institute for Health and Sport (IHES), Victoria University, Melbourne, Australia

\section{Introduction}

Caffeine (1,3,7-trimethylxanthine) is a popular ergogenic aid, widely used by athletes at all levels $[1,2]$. The performance-enhancing effects of caffeine have been studied for over 100 years, with the first known study on the subject published in 1907 [3]. Since these early studies, interest in caffeine has developed, to the point that it is now one of the most well-established ergogenic aids, with performance-enhancing effects across a wide range of exercise modalities [4].

Several meta-analyses examining the effects of caffeine ingestion on exercise performance have been conducted, exploring the effects of caffeine on a broad array of exercise tests, including 1 repetition maximum (1 RM) strength [5, 6], isokinetic peak torque [7], vertical jump height [6], power output across different exercise types [8-10], aerobic endurance performance [8, 11-15], and muscular endurance $[5,16]$. The statistically significant effect sizes from these individual meta-analyses ranged from 0.16 (for isokinetic peak torque [7]) to 0.51 (for aerobic exercise performance [13]), suggesting that caffeine can reliably enhance performance. Further systematic reviews have highlighted an ergogenic effect of caffeine on sport-specific endurance [17], power-based sports [18], and resistance exercise [19, 20]. Two metaanalyses [21,22] have reported no effect of caffeine on sprint and repeated sprint performance, although a number 
of individual studies utilizing either caffeine-containing energy drinks [23] or caffeine alone [24-27] have demonstrated a potentially ergogenic effect of caffeine on both, suggesting a need for further research in this area.

Alongside its well-established effects on a variety of physical performance tasks, caffeine also exerts acute cognitive benefits upon ingestion, especially in sleep-deprived subjects. This has been explored in military personnel, with caffeine demonstrated to improve cognitive aspects such as vigilance, memory, and mood, along with physical performance, both during overnight operations and following sleep restriction [28-30], results which have been replicated in the general public (for review, see Ruxton [31]). Similar findings have been reported in athletes. For example, Cook and colleagues [32] reported that caffeine doses of 1 and $5 \mathrm{mg} / \mathrm{kg}$ ameliorated loss of skill performance in elite rugby players following sleep restriction. In non-sleep restricted subjects, caffeine may enhance sports-specific skill performance (for review, see Baker et al. [33]). Furthermore, athletes are prone to mental fatigue, which can impair physical [34, 35] and sport-specific skill-based performance [36] and cognitive ability [37]. In mentally fatigued individuals, caffeine has been shown to enhance endurance performance [38] along with skill performance and cognitive function in sport-specific situations [39, 40], although this latter finding is equivocal [41, 42].

Given caffeine's popularity, both in its use by athletes and its interest to researchers, it is tempting to believe that we potentially know all there is to understand about the use of caffeine in sport. The purpose of this review is to explore some areas where our knowledge of caffeine's performance benefits is not clear, prompting potential directions for researchers to explore in the future.

\section{What Else Do We Need to Know About Caffeine in Sport?}

At present, the performance-enhancing effects of caffeine on a plethora of exercise modes are well-established at metaanalysis level [5-16]. As such, it is clear that caffeine is an effective ergogenic aid-but can we better understand the context around its use to better inform practice? We propose that future research should instead attempt to explore the nuances of caffeine use. Given the high prevalence of caffeine ingestion amongst athletes [1,2], such an approach is likely to yield additional performance enhancement. General caffeine guidelines recommend the consumption of 3-6 mg/ $\mathrm{kg}$ of caffeine, typically $60 \mathrm{~min}$ before the start of exercise [43]; however, recently it has become apparent that there is considerable inter-individual variation in response to such a standardized protocol, with a variety of factors potentially driving this variation [44]. A greater understanding of these factors, explored in the following sections, will, hopefully, allow for the enhanced personalization of caffeine usage guidelines in the future.

\subsection{What are the Wider, Non-direct Influences of Caffeine on Performance?}

Historically, the interest in caffeine within sports science has been on its performance-enhancing effects. However, it is important to understand the wider contexts of caffeine use, and the potential impact these could have on performance. For example, caffeine has been shown to potentially elevate feelings of anxiety [45], which is an important consideration for athletes-does pre-competition caffeine consumption increase anxiety to the extent that it becomes performance limiting? An individualized approach may be required here; some individuals may need an increase in arousal prior to some competitions, and caffeine may be an effective way to achieve this [46]. Conversely, for major competitions where anxiety and arousal are likely to be increased, pre-competition caffeine may need to be reduced, or avoided altogether, in order to protect performance [44].

Caffeine ingestion can also impact the subsequent ability to both fall asleep and achieve high-quality sleep [47, 48]. This effect is potentially prolonged, with Drake and colleagues [47] reporting that $400 \mathrm{mg}$ of caffeine, ingested $6 \mathrm{~h}$ prior to bedtime, disrupted sleep quality, reduced sleep duration, and increased sleep latency. This is of interest within sporting contexts, where competitions often occur in the evening; here, pre-competition caffeine use may have a carryover effect, reducing sleep quality and duration, and subsequently harming recovery. This was explored by Dunican and colleagues [48] in a Super Rugby team. Here, players consumed caffeine prior to an evening match; post-match salivary concentrations of caffeine were associated with an increase in sleep latency and a decrease in both sleep duration and efficiency that evening compared to baseline data. Further research is required to understand what effect, if any, caffeine-induced sleep loss may have on subsequent performance (for example, across a 2-day competition), as well as replicating these initial findings. Enhancing our understanding in this area will undoubtedly assist in the provision of individualized caffeine guidelines around competition, with a pragmatic approach most likely required; is the decrease in sleep quality following caffeine ingestion a worthwhile price to pay for enhanced performance?

Aside from affecting sleep, caffeine may also modify post-training and competition recovery. In a recent review, Loureiro and colleagues [49] reported conflicting data regarding the effects of caffeine on muscle glycogen recovery, suggesting a need for further research in this area. Interestingly, cafestol and caffeic acid-ingredients 
of coffee-appear to enhance muscle glycogen recovery [49], suggesting that the use of coffee as a means to receive caffeine pre-exercise may confer some additional benefits compared to other caffeinated mediums. In another review [20], the authors concluded that caffeine ingestion prior to resistance training may reduce the occurrence of delayed onset of muscle soreness, recommending further research to explore this. Similar results have been reported following endurance exercise [50]. However, caffeine appears to delay autonomic recovery following exercise [51, 52]. As such, future research should seek to better understand the effect of pre-exercise caffeine ingestion on post-exercise recovery, particularly given that pre-exercise caffeine intake may increase physical exertion and hence muscle damage and training load. Furthermore, a better understanding of the role of caffeine on muscle glycogen recovery may lead to the use of caffeine post-exercise as a method to enhance recovery, although the demonstrated negative effect on autonomic function would require consideration.

Furthermore, genetic variation (see Sect. 2.2) is likely to contribute to the effect of caffeine on these aspects, with single-nucleotide polymorphisms (SNPs) in ADORA2A and $D R D 2$ associated with caffeine-induced anxiety and sleep disturbances [53, 54], demonstrating an interaction between some of these remaining questions regarding the use of caffeine within sport.

\subsection{What are the Effects of Genotype on Caffeine Ergogenicity?}

Three recent reviews have explored the potential impact of genetic variation on the ergogenic effects of caffeine on performance $[44,54,55]$, with two SNPs in CYPIA2 and $A D O R A 2 A$ emerging as potential candidates. Of these, CYP1A2 is most well-explored, with at least nine studies examining its effect on caffeine ergogenicity [56-64]; for a detailed summary of these studies, readers are directed to Fulton et al. [54]. The majority of these studies utilized small sample sizes, potentially hampering their statistical power and the derivation of firm conclusions. This notion is mirrored within the results, with some studies reporting no effect of the polymorphism $[52,56,57,59,61]$ and others a modifying effect, but in different directions $[58,60,63$, 64]. In the study with the largest cohort $(n=101)$, Guest and colleagues [58] reported that moderate $(4 \mathrm{mg} / \mathrm{kg})$ doses of caffeine were ergogenic for AA genotypes, ineffective for $\mathrm{AC}$ genotypes, and ergolytic for $\mathrm{CC}$ genotypes. $\mathrm{CYP} 1 \mathrm{~A} 2$ encodes for cytochrome P450 1A2, the enzyme responsible for $\sim 95 \%$ of all caffeine metabolism [65]. Subjects with the AA genotype tend to produce more of this enzyme, and hence metabolize caffeine quicker than $\mathrm{AC}$ and $\mathrm{CC}$ genotypes [66]. A potential proposed mechanism for the impact of CYP1A2 on caffeine ergogenicity is that the downstream metabolites of caffeine (paraxanthine, theobromine, and theophylline) have additional ergogenic effects, which is why the fast-metabolizing AA genotypes experience a further advantage [63]. Additionally, as caffeine is a vasoconstrictor, $\mathrm{CC}$ genotypes might experience prolonged vasoconstriction, harming endurance performance [58]. If these mechanisms are correct-and further work should aim to elucidate thisthen there is the potential that ingestion of caffeine a greater period of time prior to exercise could improve caffeine's ergogenic effects in C allele carriers [67].

As research in this field evolves, we should be able to gain a broader understanding as to the genetic influence on the effects of caffeine, be that specifically from a performance standpoint [46] or wider aspects influencing performance, such as anxiety [68, 69], sleep disturbances [70], and habitual use [71]. There is the potential that SNPs within genes located within the dopaminergic (such as DRD2 and COMT [69, 72]), adenosine (AMPD1 [73]), and adrenergic (ADRA1A, ADRA2B, ADRB1, ADRB2, and ADRB3 [73]) systems may contribute to the demonstrated inter-individual variation in response to an acute caffeine dose within sporting contexts. This aspect also has important implications for caffeine research; if genotype does modify caffeine's ergogenic effects between individuals, then these individual differences, when averaged across groups, may be masked, providing misleading results. However, the addition of genetic information to caffeine-based research may be practically problematic, as it is costly, and we do not fully understand which genetic variants modify caffeine's ergogenic effects, meaning any potential stratification based on genotype may be incomplete.

\subsection{Does Time of Day Impact the Ergogenic Effects of Caffeine?}

There is a potential effect of circadian rhythm on performance, with some studies demonstrating that performance in a given task is better in the afternoon compared to the early morning [74-76]. Specifically, muscular abilities, such as strength, appear to peak in the evening hours [77]. For example, Guette et al. [78] reported significantly lower maximal torque production at 06:00 and 10:00 h ( 90\% of maximum values) compared to strength performance at 18:00 h ( 99\% of maximal values). As athletes often have to undertake training sessions, or even compete, early in the morning, there is an increased interest in strategies to off-set this morning performance decrement.

Given its stimulatory role, caffeine represents a potential method of mitigating the performance decrement seen in the morning hours [79], particularly as studies have demonstrated that caffeine can serve to preserve performance during periods of sleep deprivation [32, 80]. This hypothesis has been tested by a number of recent studies [79, 81-85], 
detailed in Table 1. Mora-Rodríguez and colleagues [81] demonstrated that morning caffeine ingestion increased performance to that of an evening resistance exercise session. In a later study, the same research group observed that caffeine enhanced performance in the morning but not in the evening hours [82], with similar results observed by Souissi et al. [84]. Interestingly, Mora-Rodríguez and colleagues [82] reported a higher incidence of side effects upon p.m. caffeine ingestion.

In another study [83], caffeine appeared to exert a greater ergogenic effect $(+2.3 \%)$ on $3-\mathrm{km}$ cycling time trial performance when consumed in the morning compared to the evening $(+1.4 \%)$. Again, cycling performance is generally impaired in the morning versus evening hours [86], and these differences may explain the possible greater effects of caffeine ingestion in the morning. Caution must be exercised when interpreting these results, however, as the authors utilized the magnitude-based inference method which has recently received criticism due to inflated type I error rates [87]. Finally, two studies [79, 85] have reported no effect on time of day on caffeine ergogenicity.

The morning-evening differential in performance, and the potential modifying effect of caffeine ingestion, is an important methodological consideration for researchers to keep in mind, and report in future studies. A recent meta-analysis [7] reported an ergogenic effect of caffeine on isokinetic peak force (pooled effect size 0.16). Closer scrutiny of the methods used in the included studies indicates that only a single study [88] detailed the time of day at which the exercise testing was performed, which for both the caffeine and placebo trials was between 09:00 and 12:00 h. Of the ten included studies within that meta-analysis, this study reported the largest effect size (0.53) of caffeine on isokinetic strength, potentially suggesting that the time of day of caffeine ingestion represents an important variable influencing the magnitude of caffeine's ergogenic effects.

Given the relatively sparse research around this question, future work should aim to better understand what role-if any - time of day has on the effects of caffeine. This information could further be utilized to enhance caffeine strategies for athletes, especially given the potential effects of caffeine on sleep disturbances (Sect. 2.1). This could also be important from the standpoint of travel across time zones, an increasingly frequent occurrence for high level athletes, and the associated jet lag, which has been shown to harm performance $[89,90]$. Caffeine has been demonstrated to mitigate the negative effects of jet lag on performance [91] and daytime sleepiness [92], and may assist in the retraining of circadian rhythm following a large time change [89-94], although it remains understudied in this regard $[95,96]$. Future studies carried out within the area of caffeine and circadian rhythms should consider exploring the impact of caffeine on jet lag management and time-shift in athletes. Furthermore, it would likely be worthwhile to assess whether an individual's chronotype further modifies caffeine's ergogenic effects across different times of day. Finally, researchers should report the timing of performance tests utilized within caffeine trials, in order to control for this potentially modifying variable.

\subsection{Does Caffeine Ergogenicity Vary According to Training Status?}

It has been long perpetuated in the scientific literature that the effects of caffeine on exercise performance differ between trained and untrained individuals, popularized by the work by Collomp et al. [24]. Here, seven trained and seven recreational swimmers had their swimming performance tested on two occasions (following the ingestion of placebo and caffeine), with the results revealing that only the trained swimmers experienced improvements in swimming velocity following caffeine ingestion. Similar findings were observed by Astorino et al. [97], who reported that trained individuals experienced improvements in cycling time-trial performance following caffeine ingestion, while those classified as 'active' did not.

Burke [98] argued that trained, as opposed to untrained, individuals might have higher reliability of exercise performance, and, therefore, less day-to-day performance variation. Reliability of performance may be of importance in this line of research, as tests with low reliability may increase the risk of type II errors and are, therefore, not suitable when examining small changes in performance [99]. Hypothetically, in untrained individuals, day-to-day performance variation is greater, potentially preventing the detection of small performance increases following caffeine ingestion. While such ideas are based on a solid rationale [98], studies examining the test-retest reliability of performance tests such as the Yo-Yo test [100], 400-m running [101], power output on the rowing ergometer [102], and 1 RM test [103] in trained and untrained individuals report that both populations exhibit comparable test-retest reliability. These results indicate that other factors are likely responsible for the divergent responses to caffeine ingestion between trained and untrained individuals.

Physiologically, it remains unclear why trained individuals might experience greater performance improvements than untrained subjects following caffeine ingestion. Comparing trained cyclists/triathletes to 'active' individuals, Skinner et al. [104] reported that time to peak and peak caffeine concentrations were similar in both groups. Therefore, the availability of caffeine within the blood might not explain the performance differences following caffeine ingestion in trained and untrained individuals noted by Collomp et al. [24] and Astorino et al. [97]. 


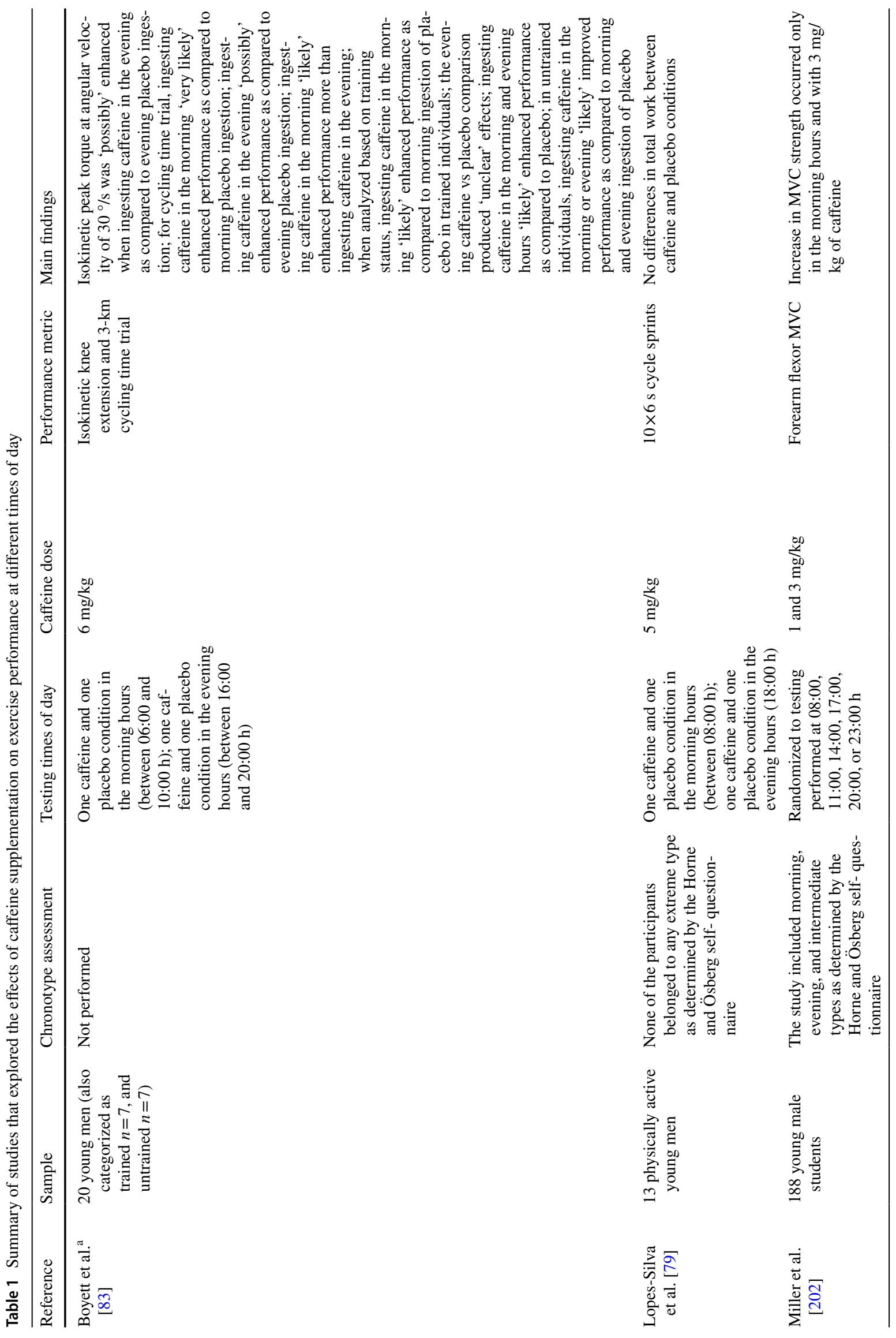




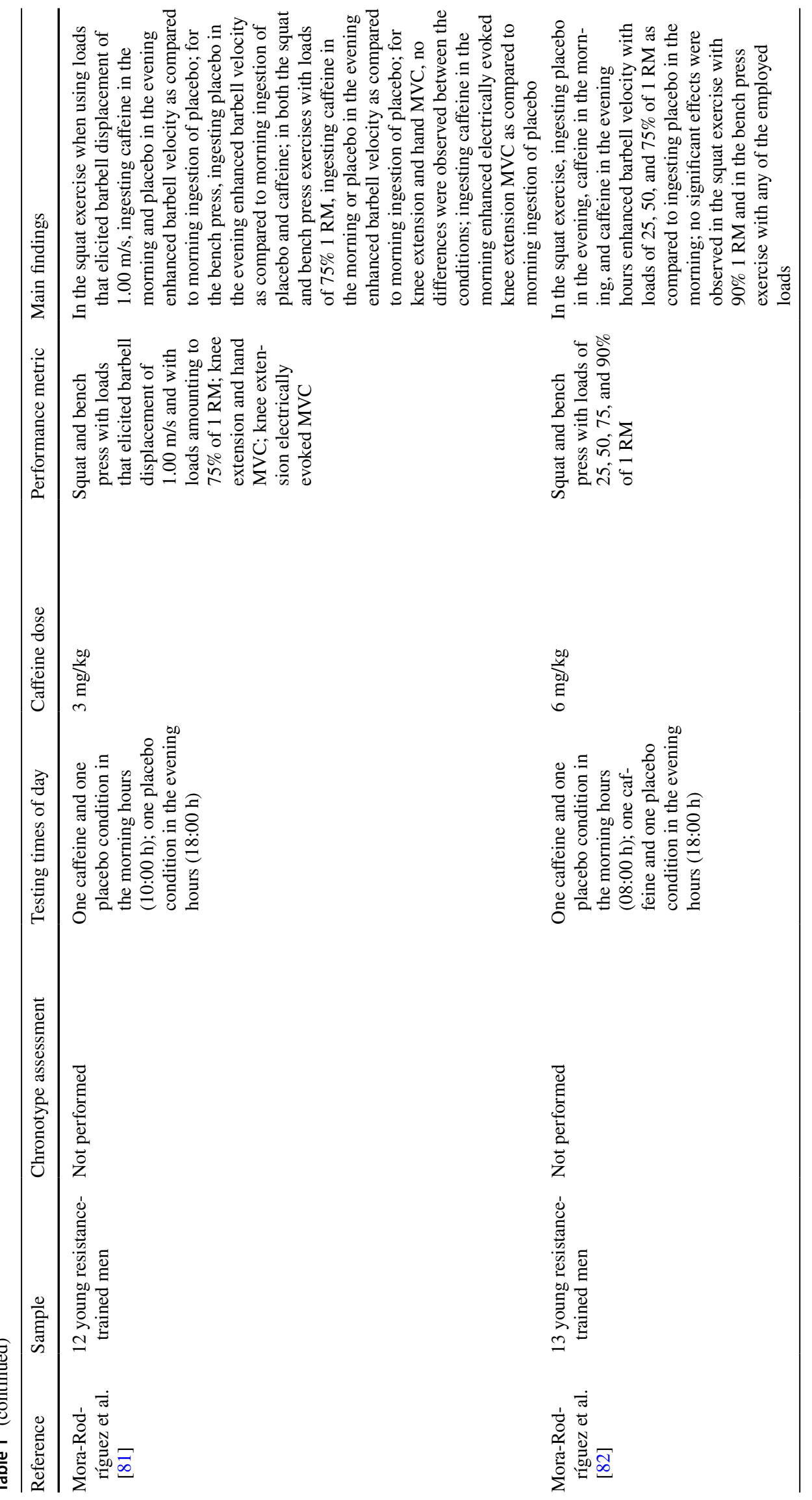




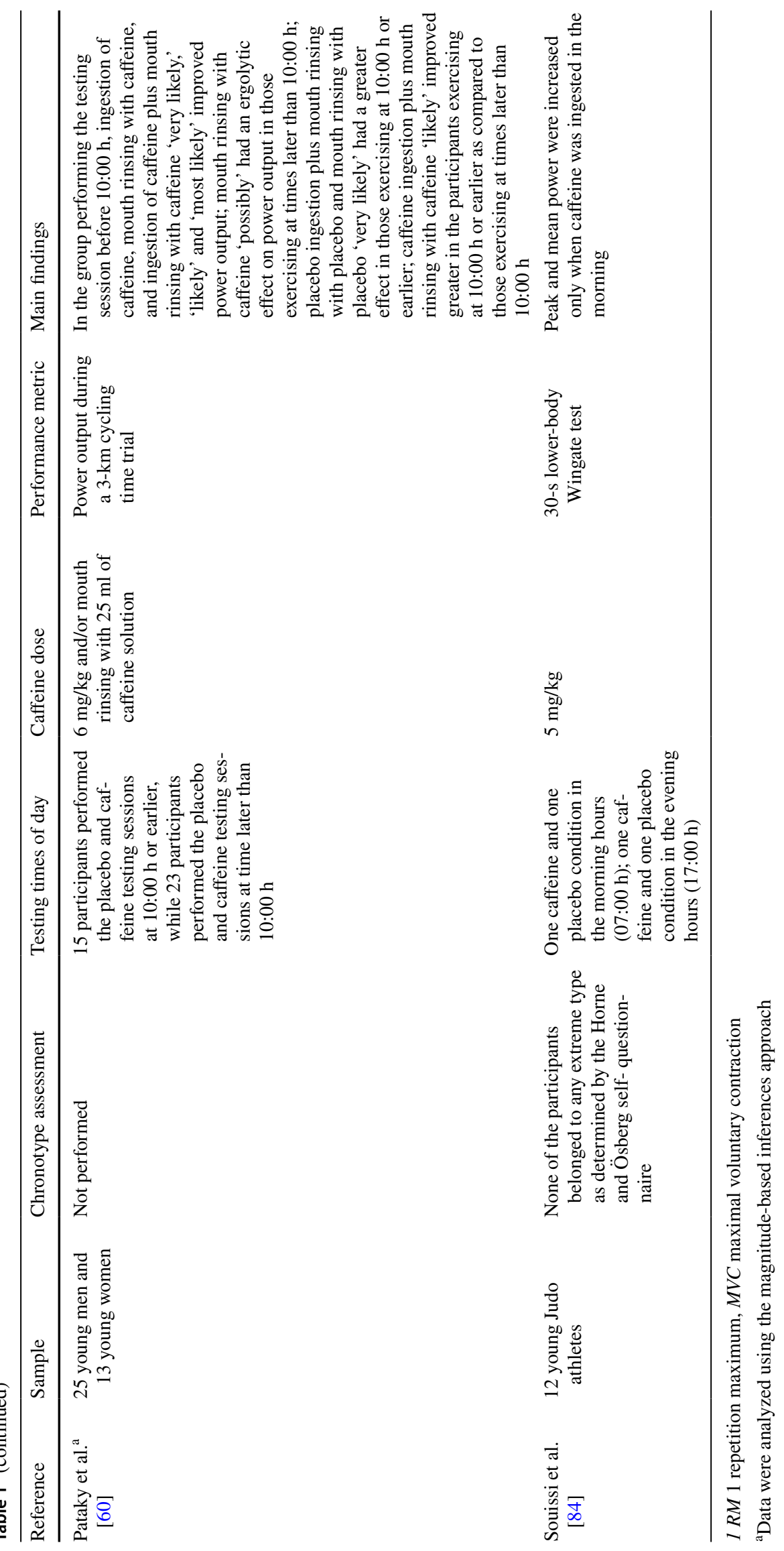


The ergogenic effects of caffeine on exercise performance predominantly appear related to caffeine's binding to adenosine receptors [105]. Mizuno et al. [106] reported that trained men have greater adenosine $A_{2 a}$ receptor densities than untrained subjects; it might be that this increase in adenosine receptor density in trained individuals allows greater binding of caffeine to these receptors, increasing the magnitude of the acute improvements in exercise performance following caffeine ingestion. This idea, however, remains speculative; in contrast to the work by Collomp et al. [24] and Astorino et al. [97], other studies report that caffeine ingestion may produce similar performance benefits in both trained and untrained (or recreationally trained) individuals [107, 109]. Moreover, in some cases, caffeine ingestion enhanced performance in untrained but not in trained individuals [109]; see Table 2 for a summary of these studies.

However, we can potentially gain some insights from animal studies utilizing isolated skeletal muscle, which provide a potentially useful model for the exploration of caffeine's ergogenic effects as animals tend not to be habitual users of caffeine, and, by bathing the muscle in a caffeine solution, differences in caffeine digestion and pharmacokinetics are largely overcome [110]. A recent study utilizing such a model [111], in which mice either underwent an 8-week exercise intervention or acted as an untrained control, suggested that $70 \mu \mathrm{M}$ of caffeine (representative of a maximal physiological dose [4]) enhanced muscle power to the same extent in the trained and untrained isolated mice muscle. This suggests that training status does not modify caffeine's ergogenic effects, at least in terms of direct muscle function. Further work in human subjects, including those with longer (i.e., multiple years) training histories, are required to further explore this hypothesis.

From a different perspective, it could be argued that in highly trained individuals (i.e., elite athletes), there is less 'potential for improvement' following caffeine ingestion, as these individuals are, by definition, towards the upper end of human exercise performance capabilities and are approaching absolute physical limits [112,113]. Given the already high performance capabilities of these individuals, it remains unclear if they can be further enhanced following caffeine ingestion. These aspects remain under-explored given the lack of studies conducted on elite athletes. Due to the limited access to elite athletes and the finite nature of these individuals, even further case studies on this topic would help to expand our current understanding of this topic [114].

In summary, the current evidence on the effects of caffeine among trained and untrained individuals is based on a handful of human studies which reported conflicting findings. This lack of studies opens up an avenue for researchers to conduct future high-quality studies on the topic as this is an area that merits further work.

\subsection{Does Caffeine Ergogenicity Vary According to Sex?}

A major limitation of the present body of research on caffeine's ergogenic effects is that the majority of studies utilize male subjects [20, 43]. As an illustration, a recent metaanalysis included nine studies, consisting of 88 pooled participants, of which only three were female [14]. A likely explanation for this difference between sexes is that females represent a slightly more complex cohort to conduct caffeine research on, as the use of oral contraceptives [115] and differences in menstrual cycle stage [116] can alter caffeine metabolization speeds, which in turn may alter the ergogenic effects of caffeine. However, a number of studies demonstrate that caffeine has an ergogenic effect in females, both in terms of resistance $[117,118]$ and endurance exercise $[119$, 120]. As such, caffeine is clearly ergogenic for females, but questions remain as to whether there are differences in optimal caffeine strategies between the sexes, especially given the differences in caffeine metabolization speed between males and females.

Several studies compare the effects of caffeine amongst males and females, reporting similar effects in both sexes [121-123], outlined in Table 3. Whilst other studies have recruited both sexes, they generally analyzed males and females together [107, 124]. However, in order to expand our understanding of potential sex differences in response to caffeine ingestion, further work should aim to recruit males and females, and undertake between-group comparisons of the sexes. A similar approach was utilized by Skinner et al. [120], who reported that the magnitude of ergogenic effects following ingestion of $3 \mathrm{mg} / \mathrm{kg}$ caffeine 90 -min prior to a cycle test was the same $(\sim 4 \%)$ between the sexes. However, there were significant differences in caffeine concentrations post-exercise, with females having a greater amount. This suggests that females do not metabolize caffeine as rapidly as males, hinting that, similar to CYP1A2 CC genotypes, females might benefit from a longer time between caffeine ingestion and exercise trials [67]; such a hypothesis requires testing.

\subsection{Does Habitual Caffeine Use Alter Its Ergogenic Effects?}

Whilst habituation is commonly identified as a factor modifying the acute response to caffeine supplementation [125], research on this topic demonstrates conflicting findings [126]. A recent review [126] explored the influence of habitual caffeine use on the ergogenic effects of an acute caffeine dose. This subject is surprisingly under-studied in human subjects, with the authors finding only four studies [127-130] utilizing a performance task. Of these, two reported a blunting (but not elimination) of caffeine's 


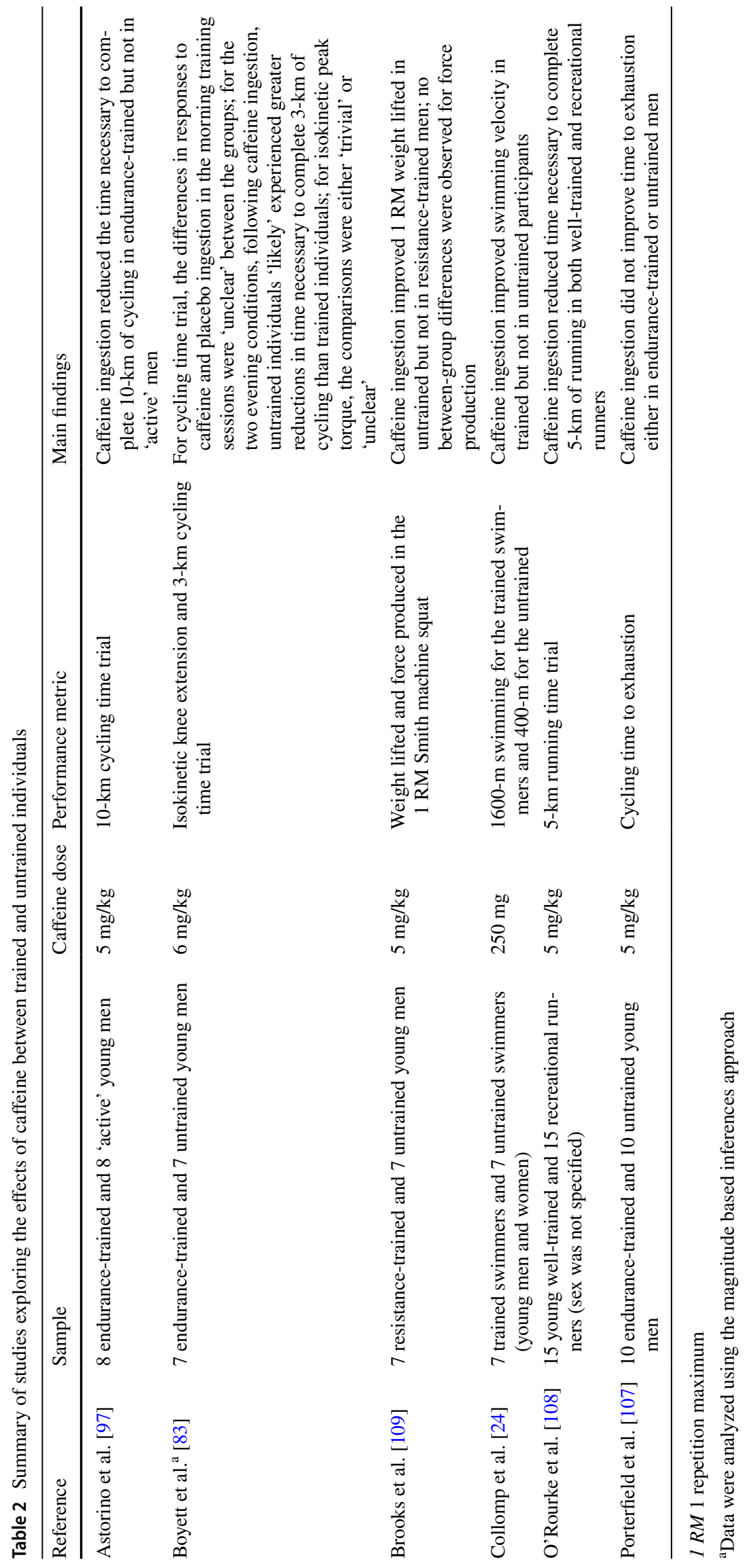


Table 3 Summary of some studies exploring the effects of caffeine between men and women

\begin{tabular}{|c|c|c|c|c|}
\hline Reference & Sample & Caffeine dose & Performance metric & Main findings \\
\hline Butts and Crowell [121] & 13 young men and 15 women & $300 \mathrm{mg}$ & Cycling time to exhaustion & $\begin{array}{l}\text { Caffeine ingestion did not improve } \\
\text { time to exhaustion in both sexes }\end{array}$ \\
\hline Sabblah et al. [122] & 10 young men and 8 women & $5 \mathrm{mg} / \mathrm{kg}$ & $\begin{array}{l}\text { Weight lifted in the squat and } \\
\text { bench press } 1 \mathrm{RM} \text {; repetitions to } \\
\text { muscle failure with } 40 \% 1 \mathrm{RM} \\
\text { in the bench press }\end{array}$ & $\begin{array}{l}\text { Caffeine ingestion enhanced weight } \\
\text { lifted in the } 1 \mathrm{RM} \text { bench press } \\
\text { in men and women; no effects of } \\
\text { caffeine were observed for } 1 \mathrm{RM} \\
\text { squat and } 40 \% 1 \mathrm{RM} \text { in the bench } \\
\text { press performance to muscle } \\
\text { failure in both sexes }\end{array}$ \\
\hline Skinner et al. [120] & 16 young men and 11 women & $3 \mathrm{mg} / \mathrm{kg}$ & Cycling time to exhaustion & $\begin{array}{l}\text { Caffeine ingestion improved time } \\
\text { to exhaustion both in men and } \\
\text { women }\end{array}$ \\
\hline Suvi et al. [123] & 13 young men and 10 women & $6 \mathrm{mg} / \mathrm{kg}$ & Walks until volitional exhaustion & $\begin{array}{l}\text { Caffeine ingestion did not improve } \\
\text { time to exhaustion in both sexes }\end{array}$ \\
\hline
\end{tabular}

$1 R M 1$ repetition maximum

acute ergogenic effects with habitual use [128, 129], and two reported no differences in response to acute caffeine ingestion between individuals with different habitual caffeine intakes $[127,130]$. These mixed results drove the authors to propose that the difference between habitual and pre-exercise caffeine dose is potentially important; specifically, they hypothesized that high habitual caffeine users perhaps require a pre-exercise caffeine dose in excess of their habitual intake [126]. Further research is required to better understand whether this is indeed the case, especially in light of the recent findings by Lara et al. [131]. Here, participants undertook a double-blind, placebo-controlled, randomized cross-over study, with subjects participating in two 20-day protocols, one with daily caffeine intake amounting to $3 \mathrm{mg} / \mathrm{kg}$, the other with the consumption of placebo capsules. At regular intervals, the subjects undertook a maximally graded time-to-exhaustion cycle ergometer test, along with a 15-s maximal cycle ergometer sprint, with the exercise bout commencing 60 min following capsule ingestion. The authors found that, whilst caffeine remained ergogenic throughout the 20-day period, its ergogenic effects were attenuated. Such a finding suggests that partial habituation may occur. Conversely, Sabol et al. [132] reported that habitual caffeine use had no effect on the ergogenic effects of caffeine in medicine ball throw and vertical jump tests, with these latest conflicting studies further highlighting the need for additional studies in this area. Relevant studies in this area are outlined in Table 4.

Alongside the issue of caffeine habituation is the issue of caffeine withdrawal as a potential method to enhance caffeine's ergogenic effects. This becomes an issue if habitual caffeine use does reduce the performance benefits associated with its ingestion, which, as discussed above, is currently unclear. In a recent review [126], the authors identified three studies directly examining the effects of caffeine withdrawal on exercise performance [133-135], with the finding that a pre-exercise caffeine withdrawal period had no impact on caffeine's ergogenic effects; this, along with the potential downside of caffeine withdrawal, led the authors to conclude that such a withdrawal period was unnecessary.

Furthermore, several methodological aspects need to be highlighted for future studies in this area. One such aspect is the reliability of the exercise test. For example, Bell and McLellan [128] explored the effects of caffeine ingestion between caffeine users and non-users utilizing a time-toexhaustion test. This may be relevant, given that these tests have been found to have lower reliability than time-trial tests [101]. Therefore, employing a test with a high measurement error can confound study results, possibly leading to erroneous inferences regarding the effects of caffeine among low and high habitual caffeine users. Similarly, the authors of this study (and other studies; e.g., Dodd et al. [127]) did not report if the questionnaire used for assessing habitual caffeine intake was previously validated. Therefore, future studies should ensure that a validated questionnaire for assessing habitual caffeine intake is used. An additional issue in previous studies investigating this topic is that they classify the participants on a broad binary spectrum as caffeine 'users' and 'non-users.' For example, Dodd et al. [127] classified non-users as those ingesting $25 \mathrm{mg}$ of caffeine per day, while high users were classified as those that ingesting $>300 \mathrm{mg} / \mathrm{day}$; therefore, individuals in the middle range of daily caffeine intake are disregarded. This may be problematic because the middle range likely represents the majority of the population ingesting caffeine; for example, the average consumption of caffeine among the healthy population in the USA is $165 \mathrm{mg} /$ day [136]. To increase their generalizability, future studies should consider using a more comprehensive range of classifying habitual caffeine 


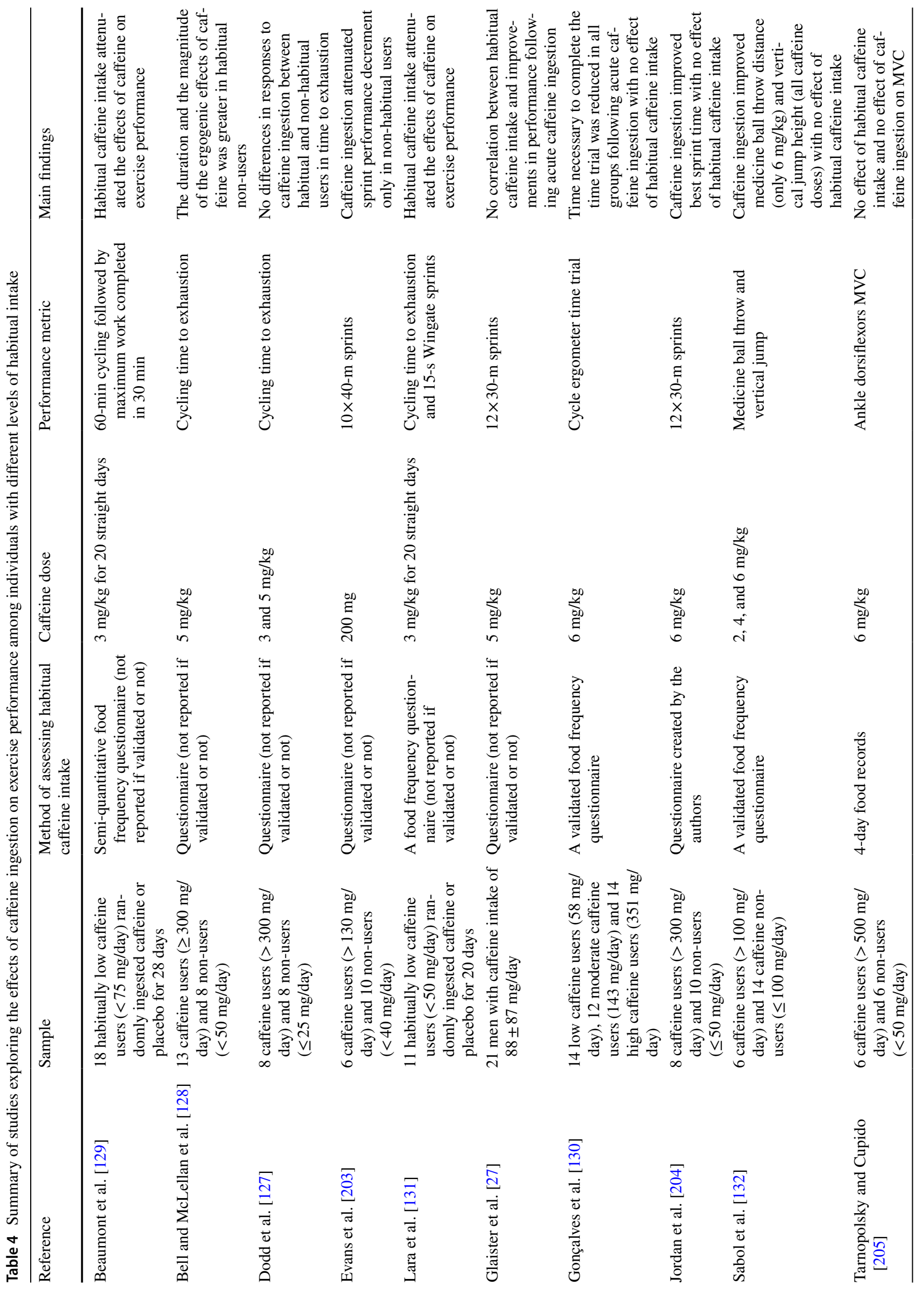


users, as recently demonstrated by Gonçalves et al. [130]. Finally, given the wide variation in caffeine concentrations both between caffeine sources and within the same caffeine source at different time points [137, 138], the accurate quantification of habitual caffeine use is problematic [139]. A potential solution is the measurement of objective markers, such as urinary caffeine output or plasma caffeine/caffeine metabolite levels [140, 141], although such an approach increases the methodological challenges.

\subsection{How Should Caffeine be Utilized Within Repeated Competitive Bouts?}

Athletes are often required to undertake numerous competitive bouts within a short time frame; for example, at the 2017 World Athlete Championships, the semi-finals and finals of the $100 \mathrm{~m}$ were separated by less than $3 \mathrm{~h}$. Whilst research has established that caffeine is ergogenic, its use around repeated competitive bouts is poorly understood [142]. There are a number of issues requiring consideration here; if the second competitive bout is within the period of time in which plasma caffeine concentrations are maintained, what effect, if any, does a second caffeine dose have? Similarly, because caffeine can increase work rate [143], is it likely to increase fatigue or muscle damage from the initial competitive bout that will carry over to the subsequent bout—and, if so, does this affect performance [144]? How might this affect subsequent sleep (Sect. 2.1)? To what extent does inter-individual variation modify these factors (Sect. 2.2)? It is important that future research replicates how athletes utilize caffeine in the real world, in order to help develop answers to these questions.

There are some initial attempts to answer these questions. For instance, Bell and McLellan [145] reported that ingestion of $5 \mathrm{mg} / \mathrm{kg}$ of caffeine prior to morning exercise acutely enhanced performance, and this ergogenic effect was maintained in a second exercise bout performed $6 \mathrm{~h}$ later. The maintenance of the ergogenic effect is likely explained by caffeine's half-life, which is generally 4-6 h [4]. In the same study, re-dosing with an additional $2.5 \mathrm{mg} / \mathrm{kg}$ of caffeine did not further improve afternoon performance, suggesting that re-dosing with caffeine prior to the second exercise bout is potentially unnecessary. In contrast, Negaresh and colleagues [146] explored the impact of single $(10 \mathrm{mg} / \mathrm{kg}$ or $4 \mathrm{mg} / \mathrm{kg}$ ) or repeated $(5 \times 2 \mathrm{mg} / \mathrm{kg})$ caffeine doses on wrestling performance, investigated using five performance tests separated by $45-180 \mathrm{~min}$. The repeated dosing approach enhanced performance relative to placebo in the initial four exercise tests, whilst the $10 \mathrm{mg} / \mathrm{kg}$ dose only enhanced the first bout, and $4 \mathrm{mg} / \mathrm{kg}$ had no ergogenic effect. Given the limited number of studies conducted thus far, further exploration in this area is required. 


\subsection{Does Caffeine Modify Training Adaptations?}

Caffeine has a clear acute ergogenic effect on exercise performance. Given that the effects of caffeine are repeatable across days [147], ultimately, practitioners are also interested in determining whether the use of caffeine, if continued over time, also impacts long-term training adaptations. The scientific attempts to answer this question are unfortunately almost non-existent. One study worth discussing is that of Malek et al. [148]; here, 36 participants were randomized to receive either a placebo $(n=18)$ or a caffeine-containing supplement (three pills equating a total of $201 \mathrm{mg}$ of caffeine; $n=18$ ) each day (on training days, 60-min pre-exercise). The training sessions consisted of treadmill running for $45 \mathrm{~min}$ and were conducted three times per week, for 8 weeks. Pre- to post-intervention, both groups experienced improvements in peak oxygen consumption $\left(V^{2} \mathrm{O}_{2 \text { peak }}\right)$, with no significant between-group differences. These initial results suggest that chronic caffeine use might not augment adaptations to long-term training. However, while interesting, this study also had several limitations. For example, there was no acute component, and therefore, it remains unclear if this supplement was even effective for acute improvements in performance. Secondly, the participants ingested a supplement that contained caffeine, but also over ten other ingredients. Therefore, any potential effect of caffeine could not be isolated.

Future studies are needed to explore this area as there is a logical basis for which caffeine might augment adaptations to training. In resistance exercise, for example, caffeine can acutely increase total volume load [5]. If continued over time, the cumulative effect of these acute performance increases might also impact hallmark resistance-training adaptations, such as skeletal muscle hypertrophy and increased strength, both of which appear to be augmented with increased volume [149, 150]. Furthermore, as caffeine ingestion pre-exercise may delay exercise-induced fatigue, individuals may be able to train for more extended periods with a higher exercise quality, which, subsequently, may enhance long-term training adaptations. Until future longterm studies are conducted, these ideas remain speculative, and future work is evidently needed.

\subsection{How Should Caffeine be Consumed?}

In the majority of caffeine-based research studies, caffeine is consumed in its anhydrous, powdered form. However, in practice, athletes consume caffeine via a broad array of mediums, including coffee [151], energy drinks [22], bars and gels [152], nasal sprays [153], and chewing gum [154]. In some cases, the caffeine itself is not ingested, but rinsed round the mouth [155], with the proposed mechanism that the caffeine molecules bind to adenosine receptors found there [156].

A summary of the research into many of these alternative methods of caffeine administration was provided in an excellent recent review by Wickham and Spriet [157], to which interested readers are directed. For many of the alternative caffeine administration methods, there is surprisingly scarce research; for example, only two studies have explored the use of caffeinated gels on sporting performance [157]. Whilst early research suggests such alternative methods may be useful, further work is required to determine their efficacy [157], and we should seek to understand the situations in which each provide the optimal benefit. As an example, when administered in the form of caffeinated chewing gum, caffeine appears to be absorbed more rapidly [158], suggesting that it could be of greater use when a quicker effect is required-for example, during the 15-min half-time period in soccer. Similarly, a caffeine mouth-rinse represents a potentially effective method of providing a final pre-competition/exercise trial caffeine dose, as research has shown ergogenic effects immediately following such a mouth rinse [157]. The use of caffeinated gels may be advantageous as caffeine has been shown to enhance glucose absorption, suggesting that, when combined with the carbohydrate found in caffeinated gels, it may enhance performance to a greater extent than a carbohydrate gel alone [159]. Finally, noningestion methods of caffeine administration may also be useful for athletes suffering from gastrointestinal distress around exercise, particularly when considering that caffeine can act as a gastric irritant [160]. Enhancing our knowledge in this area, particularly with regard to the determination of an optimal caffeine dose for each method, whether a dose-response relationship exists, if there are any advantages to repeated intakes during an exercise bout, and the optimal timing of each method, therefore holds wide future promise.

An additional way in which caffeine is ingested is via coffee [161]. Whilst coffee, as a method of caffeine ingestion, has been shown to be ergogenic [162], although not unequivocally [163], the question remains as to whether it is as effective as caffeine in isolation at improving performance. Graham [4] concluded that coffee was "probably inferior to caffeine as an ergogenic aid," and that some of its multiple compounds may reduce the ergogenic effects of caffeine. Hodgson et al. [151] reported that both caffeine and coffee, standardized to deliver a caffeine dose of $5 \mathrm{mg} / \mathrm{kg}$, were similarly efficacious in enhancing performance above placebo in a cycle ergometer test. Two studies [164, 165] compared the use of coffee and caffeine anhydrous for their ergogenic effects on strength and sprint performance, reporting similar ergogenic effects for both modalities. These results suggest a similar ergogenic effect of both caffeine and coffee, provided the caffeine dose is matched. 
Practically, the use of coffee as the main caffeine source by athletes prior to competition may be problematic. Caffeine concentrations vary between coffee blends and brands and in the same coffee source over time [137, 138, 166], although such a problem is not unique to coffee [167]. Additionally, coffee tends to be consumed whilst warm, which may cause issues with thermoregulatory control, especially in warm climates [168], and represents a potential logistical issue, as it needs to be transported to the venue in a container that maintains its temperature. However, for non-athletes looking for a pre-exercise caffeine boost, or for athletes in a more relaxed training environment, there appears to be little downside to the use of coffee as a pre-exercise performance-enhancer. Given the ubiquity of coffee consumption in modern society, further research into the ergogenic effects of coffee, when compared to caffeine alone, is warranted, including that of potential side effects such as gastrointestinal distress [162].

\subsection{What is the Optimal Dose of Caffeine?}

One of the basic questions for those interested in caffeine supplementation is "What dose of caffeine should I use?" Close scrutiny of current evidence highlights we do not have a clear answer to this question, as the large majority of studies examining the effects of caffeine ingestion on exercise performance use a single dose of caffeine. It, therefore, remains unclear if higher doses of caffeine result in greater performance-enhancing effects.

In general, studies conducted thus far utilizing different doses of caffeine do not necessarily support a linear dose-response relationship between caffeine dose and the magnitude of its ergogenic effect. Pasman et al. [169] used doses of 5, 9, and $13 \mathrm{mg} / \mathrm{kg}$, and reported that all doses were equally effective in enhancing cycling performance. Graham and Spriet [170] compared the effects of 3,6, and $9 \mathrm{mg} / \mathrm{kg}$ on performance in a time to exhaustion test, observing that only the two lower doses enhanced performance. Desbrow et al. [171] compared the effects of 3 versus $6 \mathrm{mg} / \mathrm{kg}$ and reported that both doses enhanced aerobic endurance, with no between-dose differences.

However, studies utilizing high-intensity, maximalexertion exercises performance tests report that, in certain instances, higher doses do result in greater improvements in performance. For example, Astorino et al. [172] reported that $5 \mathrm{mg} / \mathrm{kg}$ but not $2 \mathrm{mg} / \mathrm{kg}$ of caffeine increased peak torque. Pallarés et al. [173] reported that a dose of $9 \mathrm{mg} / \mathrm{kg}$ was ergogenic for contraction velocity in high-load resistance exercise (90\% of $1 \mathrm{RM}$ ), while doses of 3 and $6 \mathrm{mg} /$ $\mathrm{kg}$ were not (similar results were observed for 6-s cycling peak power output in the same study). Sabol et al. [132] found that, compared to placebo, caffeine doses of 2, 4 and $6 \mathrm{mg} / \mathrm{kg}$ were all effective in enhancing lower-body ballistic exercise performance; however, only a dose of $6 \mathrm{mg} / \mathrm{kg}$ enhanced upper-body ballistic exercise. Similarly, Tallis and Yavuz [174] reported that $6 \mathrm{mg} / \mathrm{kg}$ of caffeine, as compared to placebo, enhanced isokinetic force production, whilst a lower dose of caffeine $(3 \mathrm{mg} / \mathrm{kg})$ did not.

The divergent results for the effects of varying doses of caffeine in different exercise tasks might be explained by the mechanisms of caffeine. When ingested, caffeine elicits many physiological responses in the body, which makes it difficult to isolate the mechanism by which it enhances performance. However, there is evidence that caffeine's reduction of rating of perceived exertion (RPE) is one of the primary explanatory reasons for its ergogenic effects on aerobic exercise performance [11]. Caffeine binds to adenosine receptors, subsequently reducing RPE during exercise. McLellan and colleagues [105] suggested a threshold plasma caffeine concentration of $15-20 \mu \mathrm{M}$ (generally attained from a dose of $3 \mathrm{mg} / \mathrm{kg}$ ) is required to experience an ergogenic effect during aerobic exercise. In this context, it might be that a lower dose of caffeine (e.g., $3 \mathrm{mg} / \mathrm{kg}$ ) is sufficient for caffeine to bind to the adenosine receptors, reduce RPE, and enhance aerobic performance. Therefore, for this exercise type, higher doses (e.g., 4-6 mg/kg) may not necessarily produce a larger ergogenic effect. Here, the timing of caffeine ingestion needs to be considered. One hour of exercise has been reported to alter the responses of adenosine receptors [175], which may explain why, in some cases, low doses of caffeine, when administered during exercise, may still increase exercise performance [176].

The primary mechanisms by which caffeine increases muscular strength, muscular endurance, and power performance are potentially related to its ability to augment muscle fiber conduction velocity and motor unit recruitment [177]. It might be that increasing the dose of caffeine also increases these properties in a linear dose-response fashion, potentially explaining the findings of Astorino et al. [172] and Pallarés et al. [173]. Indeed, a meta-analysis by Warren and colleagues [16] reported a dose-response relationship between caffeine dose and muscular endurance, supporting this idea. However, many of the studies exploring the effects of caffeine on strength, power, and muscular endurance generally do not measure caffeine plasma concentrations, making it difficult to determine a minimum plasma concentration for the ergogenic effect of caffeine in this exercise type. Finally, we acknowledge that these ideas are merely hypotheses and remain to be explored in future research.

Alternatively, these contrasting findings might be related to the statistical power of the studies. Most of the studies examining the effects of varying doses of caffeine included fewer than 20 participants [19, 144, 169, 171, 178-180], as detailed in Table 5. In a study with 101 participants, Guest et al. [58] reported that doses of 2 and $4 \mathrm{mg} / \mathrm{kg}$ were comparably effective for acute increases in 10-km cycling time 
trial performance. As such, these results are the most robust evidence that greater improvements in performance are not attained by increasing the dose of caffeine.

Future studies with larger sample sizes are needed to truly determine the optimal caffeine dose. Future studies should also employ performance tests for which it is well-established that caffeine is ergogenic. For instance, Trevino et al. [180] compared the effects of 5 and $10 \mathrm{mg} / \mathrm{kg}$ of caffeine on isometric strength. Their results indicated that neither of the doses were effective for acute increases in strength; however, they tested the strength of the elbow flexors, and previous research has demonstrated that caffeine is not always ergogenic for this muscle group [177].

Until more studies using multiple doses of caffeine on exercise performance are conducted, current conclusions can only be that doses in the range from 2 to $9 \mathrm{mg} / \mathrm{kg}$ (when administered in anhydrous, powdered form) are required for acute performance-enhancing effects. Still, there remains a possibility that optimal dosages are administration time[176], task- [173], and individual-dependent [44], especially given the interactions of dose and genotype in the Guest and colleagues [58] study detailed above. Optimal doses may also depend on caffeine source, as there is evidence that very low doses of caffeine administered in caffeinated-chewing gum (e.g., an absolute dose of $100 \mathrm{mg}$ ) are also ergogenic [181]. While the question of the optimal caffeine dose for acute performance enhancement is a basic one, we are currently far from being able to answer it, and future studies should aim to explore this area further.

\subsection{Does Age Modify Caffeine Ergogenicity?}

Whilst we might typically focus on the ergogenic effects of caffeine in younger participants, caffeine's performanceenhancing effects may hold promise as a method of acutely enhancing exercise capacity, performance, and activities of daily living in older adults. Research has demonstrated that caffeine is effective in enhancing exercise performance in older adults [124, 182]; however, there is the possibility that the magnitude of ergogenic effects varies with age.

Early work by Swift and Tiplady [183] suggested that older adults were more sensitive to caffeine in terms of psychomotor changes, measured by changes in choice reaction time and attentional levels, compared to younger subjects. Utilizing an isolated mouse muscle methodology, Tallis et al. [184] reported that, whilst caffeine was ergogenic across a range of ages, the magnitude of performance improvements tended to be reduced in the muscles of the oldest (50 weeks) and youngest ( 3 weeks) mice when compared to middle-aged (10- and 30-week-old) mice. To our knowledge, these studies represent the only research to date directly comparing younger and older subjects in terms of caffeine ergogenicity, demonstrating the potential importance of further work in older adults, particularly given the health benefits of enhanced exercise performance in such a population. Additional nuance may need to be explored here, given the potential negative effects of caffeine ingestion on bone mineral density $[185,186]$ and blood pressure [187, 188], although caffeine and/or coffee consumption does appear to be protective of cognitive function with ageing [189], and tends to be associated with improved all-cause mortality [190].

\section{Conclusion}

Whilst caffeine has a clear, well-established performanceenhancing effect on exercise performance [5-18, 191], there are still many practical aspects regarding its use within sport and exercise that remain poorly understood. The aspects introduced here represent our thoughts on areas that require further exploration in order to better inform and enhance caffeine use strategies in athletes. They are not exhaustive, with other authors having suggested additional aspects. For example, Burke [142] explored the interaction of caffeine with other ingredients, which is an important consideration given that athletes often co-ingest caffeine with other ergogenic aids, such as carbohydrates and taurine in the case of caffeine-containing energy drinks, both of which are themselves capable of exerting ergogenic effects [192, 193]. Additionally, a review by Shabir et al. [194] reported potential expectancy effects of caffeine in 13 out of 17 identified studies, suggesting that if an individual believes they have consumed caffeine, and believes that caffeine is ergogenic, they are likely to experience a performance benefit, even if caffeine has not been consumed. Similarly, correct identification of administration of caffeine or placebo by study participants can modify their performance [195]. As a result, researchers should attempt to control for caffeine expectancy in intervention studies, and also collect data as to the effectiveness of their blinding procedures. Finally, given that the majority of studies on the topic of caffeine and exercise explore its effects only in laboratory conditions, as noted by Burke [98], further research should seek to replicate actual practices in sport, similar to those demonstrated in recent studies across a variety of sports, including volleyball [196], rugby [23, 197], soccer [198, 199], basketball [200], and swimming [201].

Accordingly, it is clear that our understanding of some of the nuances of caffeine and performance remains incomplete. We hope that the aspects identified within this review provide some directions for future research, allowing athletes to better harness the ergogenic effects of caffeine. 


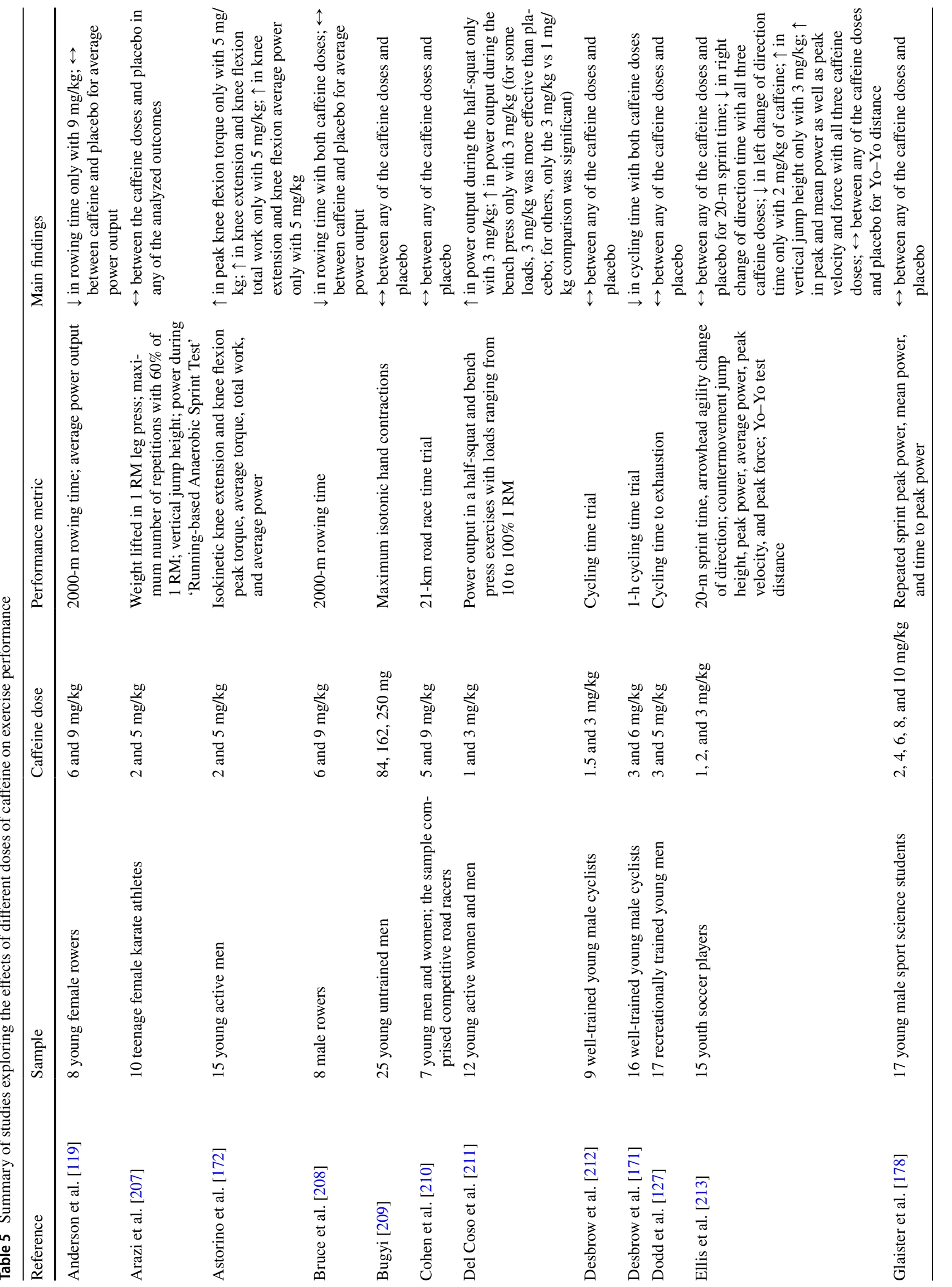




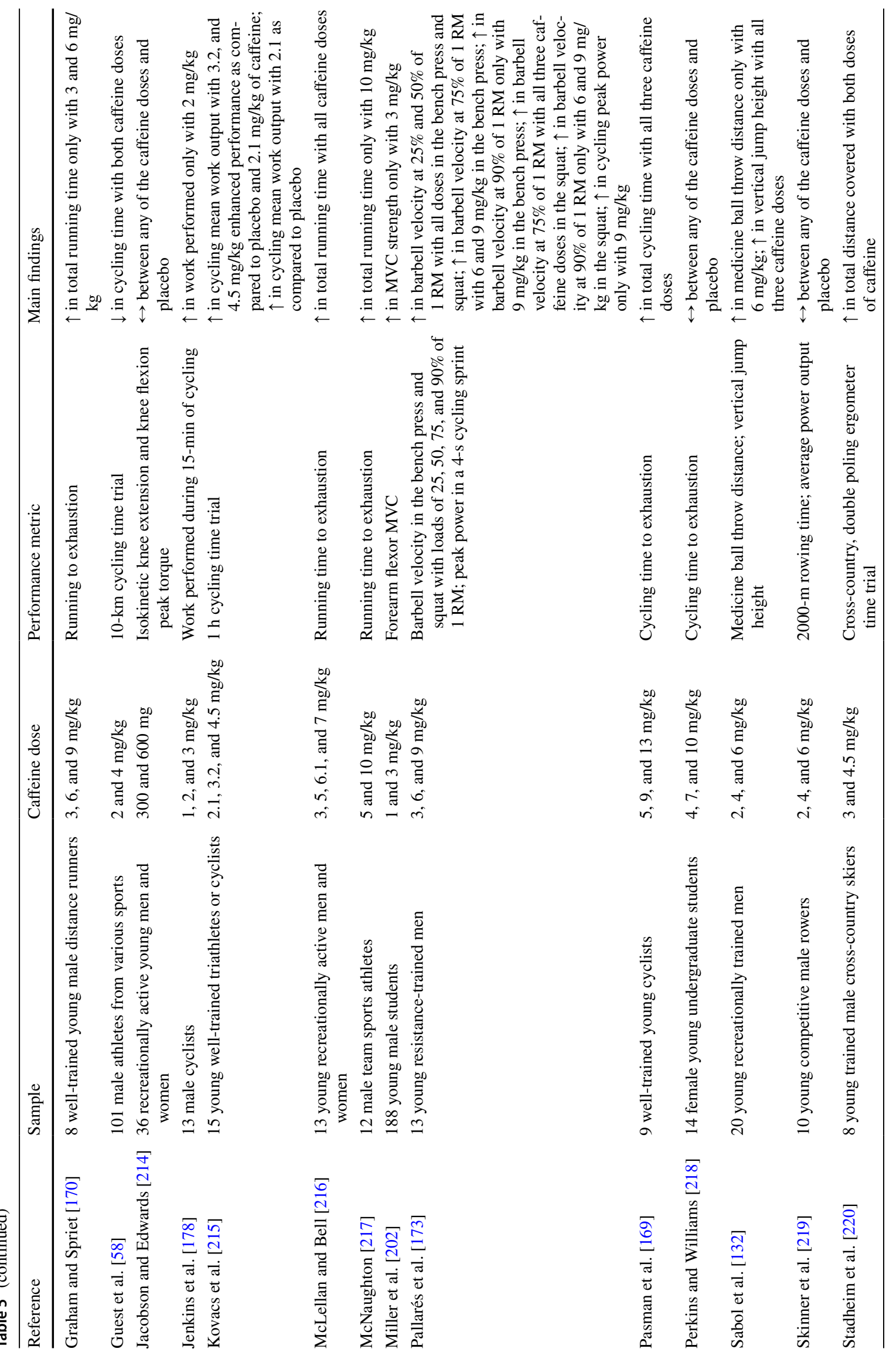




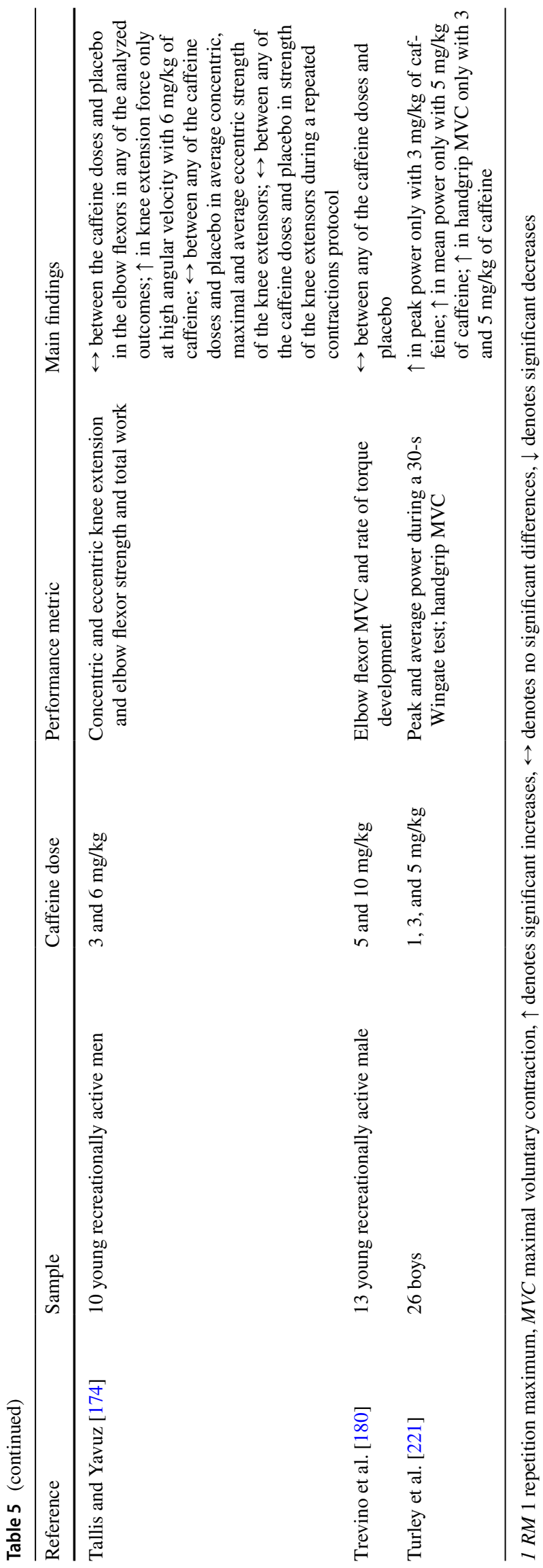

\section{Compliance with Ethical Standards}

Funding No sources of funding were used to assist in the preparation of this article.

Conflict of interest Craig Pickering is an employee of DNAFit Life Sciences, a genetic testing company. He received no financial incentives for the preparation of this manuscript. Jozo Grgic declares that he has no conflict of interest relevant to the content of this article.

Open Access This article is distributed under the terms of the Creative Commons Attribution 4.0 International License (http://creativeco mmons.org/licenses/by/4.0/), which permits unrestricted use, distribution, and reproduction in any medium, provided you give appropriate credit to the original author(s) and the source, provide a link to the Creative Commons license, and indicate if changes were made.

\section{References}

1. Del Coso J, Muñoz G, Muñoz-Guerra J. Prevalence of caffeine use in elite athletes following its removal from the World AntiDoping Agency list of banned substances. Appl Physiol Nutr Metab. 2011;36(4):555-61.

2. Van Thuyne W, Delbeke FT. Distribution of caffeine levels in urine in different sports in relation to doping control before and after the removal of caffeine from the WADA doping list. Int $\mathbf{J}$ Sports Med. 2006;27(09):745-50.

3. Rivers WH, Webber HN. The action of caffeine on the capacity for muscular work. J Physiol. 1907;36(1):33-47.

4. Graham TE. Caffeine and exercise: metabolism, endurance and performance. Sports Med. 2001;31(11):785-807.

5. Polito MD, Souza DB, Casonatto J, Farinatti P. Acute effect of caffeine consumption on isotonic muscular strength and endurance: a systematic review and meta-analysis. Sci Sports. 2016;31(3):119-28.

6. Grgic J, Trexler ET, Lazinica B, Pedisic Z. Effects of caffeine intake on muscle strength and power: a systematic review and meta-analysis. J Int Soc Sports Nutr. 2018;15(1):11.

7. Grgic J, Pickering C. The effects of caffeine ingestion on isokinetic muscular strength: a meta-analysis. J Sci Med Sport. 2019;22(3):353-60.

8. Ribeiro BG, Morales AP, Sampaio-Jorge F, de Souza Tinoco F, de Matos AA, Leite TC. Acute effects of caffeine intake on athletic performance: a systematic review and meta-analysis. Rev Chil Nutr. 2017;44(3):283-91.

9. Grgic J. Caffeine ingestion enhances Wingate performance: a meta-analysis. Eur J Sport Sci. 2018;18(2):219-25.

10. Southward K, Rutherfurd-Markwick KJ, Ali A. The effect of acute caffeine ingestion on endurance performance: a systematic review and meta-analysis. Sports Med. 2018;48(8):1913-28.

11. Doherty M, Smith PM. Effects of caffeine ingestion on exercise testing: a meta-analysis. Int J Sport Nutri Exerc Metab. 2004;14(6):626-46.

12. Doherty M, Smith PM. Effects of caffeine ingestion on rating of perceived exertion during and after exercise: a meta-analysis. Scand J Med Sci Sports. 2005;15(2):69-78.

13. Conger SA, Warren GL, Hardy MA, Millard-Stafford ML. Does caffeine added to carbohydrate provide additional ergogenic benefit for endurance? Int J Sport Nutr Exerc Metab. 2011;21(1):71-84.

14. Christensen PM, Shirai Y, Ritz C, Nordsborg NB. Caffeine and bicarbonate for speed. A meta-analysis of legal supplements 
potential for improving intense endurance exercise performance. Front Physiol. 2017;8:240.

15. Shen JG, Brooks MB, Cincotta J, Manjourides JD. Establishing a relationship between the effect of caffeine and duration of endurance athletic time trial events: a systematic review and meta-analysis. J Sci Med Sport. 2019;22(2):232-8.

16. Warren GL, Park ND, Maresca RD, Mckibans KI, MillardStafford ML. Effect of caffeine ingestion on muscular strength and endurance: a meta-analysis. Med Sci Sports Exerc. 2010;42(7):1375-87.

17. Ganio MS, Klau JF, Casa DJ, Armstrong LE, Maresh CM. Effect of caffeine on sport-specific endurance performance: a systematic review. J Strength Cond Res. 2009;23(1):315-24.

18. Astorino TA, Roberson DW. Efficacy of acute caffeine ingestion for short-term high-intensity exercise performance: a systematic review. J Strength Cond Res. 2010;24(1):257-65.

19. Davis JK, Green JM. Caffeine and anaerobic performance. Sports Med. 2009;39(10):813-32.

20. Grgic J, Mikulic P, Schoenfeld BJ, Bishop DJ, Pedisic Z. The influence of caffeine supplementation on resistance exercise: a review. Sports Med. 2019;49(1):17-30.

21. Brown SJ, Brown J, Foskett A. The effects of caffeine on repeated sprint performance in team sport athletes-a meta-analysis. Sport Sci Rev. 2013;22(1-2):25-32.

22. Souza DB, Del Coso J, Casonatto J, Polito MD. Acute effects of caffeine-containing energy drinks on physical performance: a systematic review and meta-analysis. Eur $\mathbf{J}$ Nutr. 2017;56(1):13-27.

23. Del Coso J, Portillo J, Muñoz G, Abián-Vicén J, Gonzalez-Millán C, Muñoz-Guerra J. Caffeine-containing energy drink improves sprint performance during an international rugby sevens competition. Amino Acids. 2013;44(6):1511-9.

24. Collomp K, Ahmaidi S, Chatard JC, Audran M, Prefaut C. Benefits of caffeine ingestion on sprint performance in trained and untrained swimmers. Eur J Appl Physiol Occup Physiol. 1992;64(4):377-80.

25. Schneiker KT, Bishop D, Dawson B, Hackett LP. Effects of caffeine on prolonged intermittent-sprint ability in team-sport athletes. Med Sci Sports Exerc. 2006;38(3):578-85.

26. Carr A, Dawson B, Schneiker K, Goodman C, Lay B. Effect of caffeine supplementation on repeated sprint running performance. J Sports Med Phys Fitness. 2008;48(4):472.

27. Glaister M, Howatson G, Abraham CS, Lockey RA, Goodwin JE, Foley $\mathrm{P}$, et al. Caffeine supplementation and multiple sprint running performance. Med Sci Sports Exerc. 2008;40(10):1835-40.

28. Lieberman HR, Tharion WJ, Shukitt-Hale B, Speckman KL, Tulley R. Effects of caffeine, sleep loss, and stress on cognitive performance and mood during US Navy SEAL training. Psychopharmacology. 2002;164(3):250-61.

29. McLellan TM, Kamimori GH, Voss DM, Bell DG, Cole KG, Johnson D. Caffeine maintains vigilance and improves run times during night operations for Special Forces. Aviat Space Environ Med. 2005;76(7):647-54.

30. McLellan TM, Kamimori GH, Voss DM, Tate C, Smith SJ. Caffeine effects on physical and cognitive performance during sustained operations. Aviat Space Environ Med. 2007;78(9):871-7.

31. Ruxton $\mathrm{CH}$. The impact of caffeine on mood, cognitive function, performance and hydration: a review of benefits and risks. Nutr Bull. 2008;33(1):15-25.

32. Cook CJ, Crewther BT, Kilduff LP, Drawer S, Gaviglio CM. Skill execution and sleep deprivation: effects of acute caffeine or creatine supplementation-a randomized placebo-controlled trial. J Int Soc Sports Nutr. 2011;8(1):2.

33. Baker LB, Nuccio RP, Jeukendrup AE. Acute effects of dietary constituents on motor skill and cognitive performance in athletes. Nutr Rev. 2014;72(12):790-802.
34. Smith MR, Marcora SM, Coutts AJ. Mental fatigue impairs intermittent running performance. Med Sci Sports Exerc. 2015;47(8):1682-90.

35. Van Cutsem J, Marcora S, De Pauw K, Bailey S, Meeusen R, Roelands B. The effects of mental fatigue on physical performance: a systematic review. Sports Med. 2017;47(8):1569-88.

36. Smith MR, Zeuwts L, Lenoir M, Hens N, De Jong LM, Coutts AJ. Mental fatigue impairs soccer-specific decision-making skill. J Sports Sci. 2016;34(14):1297-304.

37. Smith MR, Coutts AJ, Merlini M, Deprez D, Lenoir M, Marcora SM. Mental fatigue impairs soccer-specific physical and technical performance. Med Sci Sports Exerc. 2016;48(2):267-76.

38. Azevedo R, Silva-Cavalcante MD, Gualano B, Lima-Silva AE, Bertuzzi R. Effects of caffeine ingestion on endurance performance in mentally fatigued individuals. Eur J Appl Physiol. 2016;116(11-12):2293-303.

39. Foskett A, Ali A, Gant N. Caffeine enhances cognitive function and skill performance during simulated soccer activity. Int J Sport Nutr Exerc Metab. 2009;19(4):410-23.

40. Duncan MJ, Taylor S, Lyons M. The effect of caffeine ingestion on field hockey skill performance following physical fatigue. Res Sports Med. 2012;20(1):25-36.

41. Gant N, Ali A, Foskett A. The influence of caffeine and carbohydrate coingestion on simulated soccer performance. Int J Sport Nutr Exerc Metab. 2010;20(3):191-7.

42. Portillo J, Del Coso J, Abián-Vicén J. Effects of caffeine ingestion on skill performance during an international female rugby sevens competition. J Strength Cond Res. 2017;31(12):3351-7.

43. Goldstein ER, Ziegenfuss T, Kalman D, Kreider R, Campbell $\mathrm{B}$, Wilborn $\mathrm{C}$, et al. International society of sports nutrition position stand: caffeine and performance. J Int Soc Sports Nutr. 2010;7(1):5.

44. Pickering C, Kiely J. Are the current guidelines on caffeine use in sport optimal for everyone? Inter-individual variation in caffeine ergogenicity, and a move towards personalised sports nutrition. Sports Med. 2018;48(1):7-16.

45. Charney DS, Heninger GR, Jatlow PI. Increased anxiogenic effects of caffeine in panic disorders. Arch Gen Psychiatry. 1985;42(3):233-43.

46. Barry RJ, Rushby JA, Wallace MJ, Clarke AR, Johnstone SJ, Zlojutro I. Caffeine effects on resting-state arousal. Clin Neurophysiol. 2005;116(11):2693-700.

47. Drake C, Roehrs T, Shambroom J, Roth T. Caffeine effects on sleep taken 0, 3, or 6 hours before going to bed. J Clin Sleep Med. 2013;9(11):1195-200.

48. Dunican IC, Higgins CC, Jones MJ, Clarke MW, Murray K, Dawson B, et al. Caffeine use in a Super Rugby game and its relationship to post-game sleep. Eur J Sport Sci. 2018;18(4):513-23.

49. Loureiro LM, Reis CE, da Costa TH. Effects of coffee components on muscle glycogen recovery: a systematic review. Int J Sport Nutr Exerc Metab. 2018;28(3):284-93.

50. Caldwell AR, Tucker MA, Butts CL, McDermott BP, Vingren JL, Kunces LJ, et al. Effect of caffeine on perceived soreness and functionality following an endurance cycling event. J Strength Cond Res. 2017;31(3):638-43.

51. Bunsawat K, White DW, Kappus RM, Baynard T. Caffeine delays autonomic recovery following acute exercise. Eur J Prev Cardiol. 2015;22(11):1473-9.

52. Gonzaga LA, Vanderlei LC, Gomes RL, Valenti VE. Caffeine affects autonomic control of heart rate and blood pressure recovery after aerobic exercise in young adults: a crossover study. Sci Rep. 2017;7(1):14091.

53. Retey JV, Adam M, Khatami R, Luhmann UF, Jung HH, Berger $\mathrm{W}$, et al. A genetic variation in the adenosine $\mathrm{A} 2 \mathrm{~A}$ receptor gene (ADORA2A) contributes to individual sensitivity to caffeine effects on sleep. Clin Pharmacol Ther. 2007;81(5):692-8. 
54. Fulton J, Dinas P, Carrillo A, Edsall J, Ryan E, Ryan E. Impact of genetic variability on physiological responses to caffeine in humans: a systematic review. Nutrients. 2018;10(10):1373.

55. Southward K, Rutherfurd-Markwick K, Badenhorst C, Ali A. The role of genetics in moderating the inter-individual differences in the ergogenicity of caffeine. Nutrients. 2018;10(10):1352.

56. Algrain HA, Thomas RM, Carrillo AE, Ryan EJ, Kim CH, Let$\tan \mathrm{RB}$, et al. The effects of a polymorphism in the cytochrome P450 CYP1A2 gene on performance enhancement with caffeine in recreational cyclists. J Caffeine Res. 2016;6(1):34-9.

57. Giersch GE, Boyett JC, Hargens TA, Luden ND, Saunders MJ, Daley H, et al. The effect of the CYP1A2-163 C > A polymorphism on caffeine metabolism and subsequent cycling performance. J Caffeine Adenosine Res. 2018;8(2):65-70.

58. Guest N, Corey P, Vescovi J, El-Sohemy A. Caffeine, CYP1A2 genotype, and endurance performance in athletes. Med Sci Sports Exerc. 2018;50(8):1570-8.

59. Klein CS, Clawson A, Martin M, Saunders MJ, Flohr JA, Bechtel MK, et al. The effect of caffeine on performance in collegiate tennis players. J Caffeine Res. 2012;2(3):111-6.

60. Pataky MW, Womack CJ, Saunders MJ, Goffe JL, D'lugos AC, El-Sohemy A, et al. Caffeine and 3-km cycling performance: effects of mouth rinsing, genotype, and time of day. Scand J Med Sci Sports. 2016;26(6):613-9.

61. Puente C, Abián-Vicén J, Del Coso J, Lara B, Salinero JJ. The CYP1A2-163C > A polymorphism does not alter the effects of caffeine on basketball performance. PLoS One. 2018;13(4):e0195943.

62. Salinero JJ, Lara B, Ruiz-Vicente D, Areces F, Puente-Torres C, Gallo-Salazar C, et al. CYP1A2 genotype variations do not modify the benefits and drawbacks of caffeine during exercise: a pilot study. Nutrients. 2017;9(3):269.

63. Womack CJ, Saunders MJ, Bechtel MK, Bolton DJ, Martin M, Luden ND, et al. The influence of a CYP1A2 polymorphism on the ergogenic effects of caffeine. J Int Soc Sports Nutr. 2012;9(1):7.

64. Rahimi R. The effect of CYP1A2 genotype on the ergogenic properties of caffeine during resistance exercise: a randomized, double-blind, placebo-controlled, crossover study. Ir J Med Sci. 2019;188(1):337-45.

65. Gu L, Gonzalez FJ, Kalow W, Tang BK. Biotransformation of caffeine, paraxanthine, theobromine and theophylline by cDNA-expressed human CYP1A2 and CYP2E1. Pharmacogenetics. 1992;2(2):73-7.

66. Sachse C, Brockmöller J, Bauer S, Roots I. Functional significance of a $\mathrm{C} \rightarrow \mathrm{A}$ polymorphism in intron 1 of the cytochrome P450 CYP1A2 gene tested with caffeine. Br J Clin Pharmacol. 1999;47(4):445-9.

67. Pickering C. Caffeine, CYP1A2 genotype, and sports performance: is timing important? Ir J Med Sci. 2019;188(1):349-50.

68. Alsene K, Deckert J, Sand P, de Wit H. Association between A 2a receptor gene polymorphisms and caffeine-induced anxiety. Neuropsychopharmacology. 2003;28(9):1694.

69. Childs E, Hohoff C, Deckert J, Xu K, Badner J, De Wit H. Association between ADORA2A and DRD2 polymorphisms and caffeine-induced anxiety. Neuropsychopharmacology. 2008;33(12):2791-800.

70. Byrne EM, Johnson J, McRae AF, Nyholt DR, Medland SE, Gehrman PR, et al. A genome-wide association study of caffeine-related sleep disturbance: confirmation of a role for a common variant in the adenosine receptor. Sleep. 2012;35(7):967-75.

71. Cornelis MC, El-Sohemy A, Campos H. Genetic polymorphism of the adenosine A2A receptor is associated with habitual caffeine consumption. Am J Clin Nutr. 2007;86(1):240-4.
72. Brathwaite JM, Da Costa LA, El-Sohemy A. Catechol-O-methyltransferase genotype is associated with self-reported increased heart rate following caffeine consumption. J Caffeine Res. 2011;1(2):123-30.

73. De Caterina R, El-Sohemy A. Moving towards specific nutrigenetic recommendation algorithms: caffeine, genetic variation and cardiovascular risk. J Nutrigenet Nutrigenomics. 2016;9(2-4):106-15.

74. Reilly T, Waterhouse J. Sports performance: is there evidence that the body clock plays a role? Eur J Appl Physiol. 2009;106(3):321-32.

75. Racinais S, Perrey S, Denis R, Bishop D. Maximal power, but not fatigability, is greater during repeated sprints performed in the afternoon. Chronobiol Int. 2010;27(4):855-64.

76. Fernandes AL, Lopes-Silva JP, Bertuzzi R, Casarini DE, Arita DY, Bishop DJ, et al. Effect of time of day on performance, hormonal and metabolic response during a 1000-M cycling time trial. PLoS One. 2014;9(10):e109954.

77. Grgic J, Lazinica B, Garofolini A, Schoenfeld BJ, Saner NJ, Mikulic P. The effects of time of day-specific resistance training on adaptations in skeletal muscle hypertrophy and muscle strength: a systematic review and meta-analysis. Chronobiol Int. 2019;36(4):449-60.

78. Guette M, Gondin J, Martin A. Time-of-day effect on the torque and neuromuscular properties of dominant and non-dominant quadriceps femoris. Chronobiol Int. 2005;22(3):541-58.

79. Lopes-Silva JP, Santos JFDS, Franchini E. Can caffeine supplementation reverse the effect of time of day on repeatedsprint exercise performance? Appl Physiol Nutr Metab. 2019;44(2):187-93.

80. Souissi M, Abedelmalek S, Bou Dhiba D, Theodoros Nikolaidis $\mathrm{P}$, Ben Awicha $\mathrm{H}$, Chtourou $\mathrm{H}$, et al. Morning caffeine ingestion increases cognitive function and short-term maximal performance in footballer players after partial sleep deprivation. Biol Rhythm Res. 2015;46(5):617-29.

81. Mora-Rodríguez R, Pallarés JG, López-Samanes Á, Ortega JF, Fernández-Elías VE. Caffeine ingestion reverses the circadian rhythm effects on neuromuscular performance in highly resistance-trained men. PLoS One. 2012;7(4):e33807.

82. Mora-Rodríguez R, Pallarés JG, López-Gullón JM, LópezSamanes Á, Fernández-Elías VE, Ortega JF. Improvements on neuromuscular performance with caffeine ingestion depend on the time-of-day. J Sci Med Sport. 2015;18(3):338-42.

83. Boyett JC, Giersch GE, Womack CJ, Saunders MJ, Hughey CA, Daley HM, et al. Time of day and training status both impact the efficacy of caffeine for short duration cycling performance. Nutrients. 2016;8(10):639.

84. Souissi M, Abedelmalek S, Chtourou H, Boussita A, Hakim A, Sahnoun Z. Effects of time-of-day and caffeine ingestion on mood states, simple reaction time, and short-term maximal performance in elite judoists. Biol Rhythm Res. 2013;44(6):897-907.

85. Sweeney K. Caffeine mouth rinsing in the fed state does not enhance $3-\mathrm{km}$ cycling performance in the morning or evening. 2016. https://commons.lib.jmu.edu/honors201019/248. Accessed 8 Apr 2019.

86. Atkinson G, Todd C, Reilly T, Waterhouse J. Diurnal variation in cycling performance: influence of warm-up. J Sports Sci. 2005;23(3):321-9.

87. Sainani KL. The problem with "magnitude-based inference". Med Sci Sports Exerc. 2018;50(10):2166-76.

88. Duncan MJ, Thake CD, Downs PJ. Effect of caffeine ingestion on torque and muscle activity during resistance exercise in men. Muscle Nerve. 2014;50(4):523-7.

89. Lee A, Galvez JC. Jet lag in athletes. Sports Health. 2012;4(3):211-6. 
90. Forbes-Robertson S, Dudley E, Vadgama P, Cook C, Drawer S, Kilduff L. Circadian disruption and remedial interventions. Sports Med. 2012;42(3):185-208.

91. Lagarde D, Chappuis B, Billaud PF, Ramont L, Chauffard F, French J. Evaluation of pharmacological aids on physical performance after a transmeridian flight. Med Sci Sports Exerc. 2001;33(4):628-34.

92. Beaumont M, Batejat D, Pierard C, Van Beers P, Denis JB, Coste $\mathrm{O}$, et al. Caffeine or melatonin effects on sleep and sleepiness after rapid eastward transmeridian travel. J Appl Physiol. 2004;96(1):50-8.

93. Piérard C, Beaumont M, Enslen M, Chauffard F, Tan DX, Reiter RJ, et al. Resynchronization of hormonal rhythms after an eastbound flight in humans: effects of slow-release caffeine and melatonin. Eur J Appl Physiol. 2001;85(1-2):144-50.

94. Samuels CH. Jet lag and travel fatigue: a comprehensive management plan for sport medicine physicians and high-performance support teams. Clin J Sport Med. 2012;22(3):268-73.

95. Kolla BP, Auger RR. Jet lag and shift work sleep disorders: how to help reset the internal clock. Cleve Clin J Med. 2011;78(10):675-84.

96. Arendt J. Approaches to the pharmacological management of jet lag. Drugs. 2018;78(14):1419-32.

97. Astorino TA, Cottrell T, Talhami Lozano A, Aburto-Pratt $\mathrm{K}$, Duhon J. Effect of caffeine on RPE and perceptions of pain, arousal, and pleasure/displeasure during a cycling time trial in endurance trained and active men. Physiol Behav. 2012;106(2):211-7.

98. Burke LM. Caffeine and sports performance. Appl Physiol Nutr Metab. 2008;33(6):1319-34.

99. Currell K, Jeukendrup AE. Validity, reliability and sensitivity of measures of sporting performance. Sports Med. 2008;38(4):297-316.

100. Póvoas SC, Castagna C, da Costa Soares JM, Silva P, CoelhoE-Silva MJ, Matos F, et al. Reliability and construct validity of Yo-Yo tests in untrained and soccer-trained schoolgirls aged 9-16. Pediatr Exerc Sci. 2016;28(2):321-30.

101. Nimmerichter A, Steindl M, Williams CA. Reliability of the single-visit field test of critical speed in trained and untrained adolescents. Sports. 2015;3(4):358-68.

102. Metikos B, Mikulic P, Sarabon N, Markovic G. Peak power output test on a rowing ergometer: a methodological study. J Strength Cond Res. 2015;29(10):2919-25.

103. McCurdy K, Langford GA, Cline AL, Doscher M, Hoff R. The reliability of 1- and 3RM tests of unilateral strength in trained and untrained men and women. J Sports Sci Med. 2004;3(3):190-6.

104. Skinner TL, Jenkins DG, Leveritt MD, McGorm A, Bolam KA, Coombes JS, et al. Factors influencing serum caffeine concentrations following caffeine ingestion. J Sci Med Sport. 2014;17(5):516-20.

105. McLellan TM, Caldwell JA, Lieberman HR. A review of caffeine's effects on cognitive, physical and occupational performance. Neurosci Biobehav Rev. 2016;71:294-312.

106. Mizuno M, Kimura Y, Tokizawa K, Ishii K, Oda K, Sasaki T, et al. Greater adenosine $\mathrm{A}(2 \mathrm{~A})$ receptor densities in cardiac and skeletal muscle in endurance-trained men: a [11C]TMSX PET study. Nucl Med Biol. 2005;32(8):831-6.

107. Porterfield S, Linderman J, Laubach L, Daprano C. Comparison of the effect of caffeine ingestion on time to exhaustion between endurance trained and untrained men. J Exerc Physiol Online. 2013;16(5):90-8.

108. O'Rourke MP, O'Brien BJ, Knez WL, Paton CD. Caffeine has a small effect on 5-km running performance of well-trained and recreational runners. J Sci Med Sport. 2008;11(2):231-3.
109. Brooks JH, Wyld K, Chrismas BCR. Acute effects of caffeine on strength performance in trained and untrained individuals. J Athl Enhancement. 2015;4:6

110. Tallis J, Duncan MJ, James RS. What can isolated skeletal muscle experiments tell us about the effects of caffeine on exercise performance? Br J Pharmacol. 2015;172(15):3703-13.

111. Tallis J, Higgins MF, Cox VM, Duncan MJ, James RS. An exercise-induced improvement in isolated skeletal muscle contractility does not affect the performance-enhancing benefit of $70 \mu \mathrm{mol} 1^{-1}$ caffeine treatment. J Exp Biol. 2018;221(21):jeb190132.

112. Berthelot G, Sedeaud A, Marck A, Antero-Jacquemin J, Schipman J, Saulière G, et al. Has athletic performance reached its peak? Sports Med. 2015;45(9):1263-71.

113. Haugen T, Paulsen G, Seiler S, Sandbakk Ø. New records in human power. Int J Sports Physiol Perform. 2018;13(6):678-86.

114. Halperin I. Case studies in exercise and sport sciences: a powerful tool to bridge the science-practice gap. Int J Sports Physiol Perform. 2018;13(6):824-5.

115. Rietveld EC, Broekman MM, Houben JJ, Eskes TK, Van Rossum JM. Rapid onset of an increase in caffeine residence time in young women due to oral contraceptive steroids. Eur J Clin Pharmacol. 1984;26(3):371-3.

116. Lane JD, Steege JF, Rupp SL, Kuhn CM. Menstrual cycle effects on caffeine elimination in the human female. Eur J Clin Pharmacol. 1992;43(5):543-6.

117. Goldstein E, Jacobs PL, Whitehurst M, Penhollow T, Antonio J. Caffeine enhances upper body strength in resistance-trained women. J Int Soc Sports Nutr. 2010;7(1):18.

118. Beck TW, Housh TJ, Schmidt RJ, Johnson GO, Housh DJ, Coburn JW, et al. The acute effects of a caffeine-containing supplement on strength, muscular endurance, and anaerobic capabilities. J Strength Cond Res. 2006;20(3):506-10.

119. Anderson ME, Bruce CR, Fraser SF, Stepto NK, Klein R, Hopkins WG, et al. Improved 2000-meter rowing performance in competitive oarswomen after caffeine ingestion. Int J Sport Nutr Exerc Metab. 2000;10(4):464-75.

120. Skinner TL, Desbrow B, Arapova J, Schaumberg MA, Osborne J, Grant GD, et al. Women experience the same ergogenic response to caffeine as men. Med Sci Sports Exerc. 2019. https://doi. org/10.1249/mss.0000000000001885.

121. Butts NK, Crowell D. Effect of caffeine ingestion on cardiorespiratory endurance in men and women. Res Q Exerc Sport. 1985;56(4):301-5.

122. Sabblah S, Dixon D, Bottoms L. Sex differences on the acute effects of caffeine on maximal strength and muscular endurance. Comp Exerc Physiol. 2015;11(2):89-94.

123. Suvi S, Timpmann S, Tamm M, Aedma M, Kreegipuu K, Ööpik V. Effects of caffeine on endurance capacity and psychological state in young females and males exercising in the heat. Appl Physiol Nutr Metab. 2017;42(1):68-76.

124. Norager CB, Jensen MB, Madsen MR, Laurberg S. Caffeine improves endurance in 75-yr-old citizens: a randomized, double-blind, placebo-controlled, crossover study. J Appl Physiol. 2005;99(6):2302-6.

125. Sökmen B, Armstrong LE, Kraemer WJ, Casa DJ, Dias JC, Judelson DA, et al. Caffeine use in sports: considerations for the athlete. J Strength Cond Res. 2008;22(3):978-86.

126. Pickering C, Kiely J. What should we do about habitual caffeine use in athletes? Sports Med. 2018. https://doi.org/10.1007/ s40279-018-0980-7.

127. Dodd SL, Brooks E, Powers SK, Tulley R. The effects of caffeine on graded exercise performance in caffeine naive versus habituated subjects. Eur J Appl Physiol Occup Physiol. 1991;62(6):424-9. 
128. Bell DG, McLellan TM. Exercise endurance 1, 3, and $6 \mathrm{~h}$ after caffeine ingestion in caffeine users and nonusers. J Appl Physiol. 2002;93(4):1227-34.

129. Beaumont R, Cordery P, Funnell M, Mears S, James L, Watson P. Chronic ingestion of a low dose of caffeine induces tolerance to the performance benefits of caffeine. J Sports Sci. 2017;35(19):1920-7.

130. Gonçalves LD, Painelli VD, Yamaguchi G, Oliveira LF, Saunders B, da Silva RP, et al. Dispelling the myth that habitual caffeine consumption influences the performance response to acute caffeine supplementation. J Appl Physiol. 2017;123(1):213-20.

131. Lara B, Ruiz-Moreno C, Salinero JJ, Del Coso J. Time course of tolerance to the performance benefits of caffeine. PLoS ONE. 2019;14(1):e0210275.

132. Sabol F, Grgic J, Mikulic P. The effects of three different doses of caffeine on jumping and throwing performance: a randomized, double-blind, crossover study. Int J Sport Physiol Perform. 2019. https://doi.org/10.1123/ijspp.2018-0884.

133. Fisher SM, McMurray RG, Berry M, Mar MH, Forsythe WA. Influence of caffeine on exercise performance in habitual caffeine users. Int J Sports Med. 1986;7(05):276-80.

134. Van Soeren MH, Graham TE. Effect of caffeine on metabolism, exercise endurance, and catecholamine responses after withdrawal. J Appl Physiol. 1998;85(4):1493-501.

135. Irwin C, Desbrow B, Ellis A, O'Keeffe B, Grant G, Leveritt M. Caffeine withdrawal and high-intensity endurance cycling performance. J Sports Sci. 2011;29(5):509-15.

136. Mitchell DC, Knight CA, Hockenberry J, Teplansky R, Hartman TJ. Beverage caffeine intakes in the U.S. Food Chem Toxicol. 2014;63:136-42.

137. Desbrow B, Hughes R, Leveritt M, Scheelings P. An examination of consumer exposure to caffeine from retail coffee outlets. Food Chem Toxicol. 2007;45(9):1588-92.

138. Desbrow B, Henry M, Scheelings P. An examination of consumer exposure to caffeine from commercial coffee and coffeeflavoured milk. J Food Compost Anal. 2012;28(2):114-8.

139. Areta JL, Irwin C, Desbrow B, et al. Inaccuracies in caffeine intake quantification and other important limitations in recent publication by Gonçalves et al. J Appl Physiol. 2017;123(5):1414

140. Lelo A, Miners JO, Robson R, Birkett DJ. Assessment of caffeine exposure: caffeine content of beverages, caffeine intake, and plasma concentrations of methylxanthines. Clin Pharmacol Ther. 1986;39(1):54-9.

141. Carrillo JA, Christensen M, Ramos SI, Alm C, Dahl ML, Benítez $\mathrm{J}$, et al. Evaluation of caffeine as an in vivo probe for CYP1A2 using measurements in plasma, saliva, and urine. Ther Drug Monit. 2000;22(4):409-17.

142. Burke LM. Practical issues in evidence-based use of performance supplements: supplement interactions, repeated use and individual responses. Sports Med. 2017;47(1):79-100.

143. Cole KJ, Costill DL, Starling RD, Goodpaster BH, Trappe SW, Fink WJ. Effect of caffeine ingestion on perception of effort and subsequent work production. Int J Sport Nutr. 1996;6(1):14-23.

144. Stadheim HK, Spencer M, Olsen R, Jensen J. Caffeine and performance over consecutive days of simulated competition. Med Sci Sports Exerc. 2014;46(9):1787-96.

145. Bell DG, McLellan TM. Effect of repeated caffeine ingestion on repeated exhaustive exercise endurance. Med Sci Sports Exerc. 2003;35(8):1348-54.

146. Negaresh R, Del Coso J, Mokhtarzade M, Lima-Silva AE, Baker JS, Willems ME, et al. Effects of different dosages of caffeine administration on wrestling performance during a simulated tournament. Eur J Sport Sci. 2018. https://doi.org/10.1080/17461 391.2018.1534990.
147. Astorino TA, Cottrell T, Lozano AT, Aburto-Pratt K, Duhon J. Increases in cycling performance in response to caffeine ingestion are repeatable. Nutr Res. 2012;32(2):78-84.

148. Malek MH, Housh TJ, Coburn JW, Beck TW, Schmidt RJ, Housh DJ, et al. Effects of eight weeks of caffeine supplementation and endurance training on aerobic fitness and body composition. J Strength Cond Res. 2006;20(4):751-5.

149. Schoenfeld BJ, Ogborn D, Krieger JW. Dose-response relationship between weekly resistance training volume and increases in muscle mass: a systematic review and meta-analysis. J Sports Sci. 2017;35(11):1073-82.

150. Ralston GW, Kilgore L, Wyatt FB, Baker JS. The effect of weekly set volume on strength gain: a meta-analysis. Sports Med. 2017;47(12):2585-601.

151. Hodgson AB, Randell RK, Jeukendrup AE. The metabolic and performance effects of caffeine compared to coffee during endurance exercise. PLoS ONE. 2013;8(4):e59561.

152. Cooper R, Naclerio F, Allgrove J, Larumbe-Zabala E. Effects of a carbohydrate and caffeine gel on intermittent sprint performance in recreationally trained males. Eur J Sport Sci. 2014;14(4):353-61.

153. De Pauw K, Roelands B, Van Cutsem J, Marusic U, Torbeyns $\mathrm{T}$, Meeusen R. Electro-physiological changes in the brain induced by caffeine or glucose nasal spray. Psychopharmacology. 2017;234(1):53-62.

154. Lane SC, Hawley JA, Desbrow B, Jones AM, Blackwell JR, Ross ML, et al. Single and combined effects of beetroot juice and caffeine supplementation on cycling time trial performance. Appl Physiol Nutr Metab. 2013;39(9):1050-7.

155. Beaven CM, Maulder P, Pooley A, Kilduff L, Cook C. Effects of caffeine and carbohydrate mouth rinses on repeated sprint performance. Appl Physiol Nutr Metab. 2013;38(6):633-7.

156. Clarke ND, Kornilios E, Richardson DL. Carbohydrate and caffeine mouth rinses do not affect maximum strength and muscular endurance performance. J Strength Cond Res. 2015;29(10):2926-31.

157. Wickham KA, Spriet LL. Administration of caffeine in alternate forms. Sports Med. 2018;48(S1):79-91.

158. Kamimori GH, Karyekar CS, Otterstetter R, Cox DS, Balkin TJ, Belenky GL, et al. The rate of absorption and relative bioavailability of caffeine administered in chewing gum versus capsules to normal healthy volunteers. Int J Pharm. 2002;234(1-2):159-67.

159. Yeo SE, Jentjens RL, Wallis GA, Jeukendrup AE. Caffeine increases exogenous carbohydrate oxidation during exercise. $\mathrm{J}$ Appl Physiol. 2005;99(3):844-50.

160. Boekema PJ, Samsom M, van Berge Henegouwen GP, Smout AJ Coffee and gastrointestinal function: facts and fiction: a review. Scand J Gastroenterol Suppl. 1999;230:35-9.

161. Heckman MA, Weil J, De Mejia EG. Caffeine (1, 3, 7-trimethylxanthine) in foods: a comprehensive review on consumption, functionality, safety, and regulatory matters. J Food Sci. 2010;75(3):77-87.

162. Higgins S, Straight CR, Lewis RD. The effects of preexercise caffeinated coffee ingestion on endurance performance: an evidencebased review. Int J Sport Nutr Exerc Metab. 2016;26(3):221-39.

163. Marques AC, Jesus AA, Giglio BM, Marini AC, Lobo PC, Mota JF, et al. Acute caffeinated coffee consumption does not improve time trial performance in an 800-m run: a randomized, double-blind, crossover, placebo-controlled study. Nutrients. 2018;10(6):657.

164. Richardson DL, Clarke ND. Effect of coffee and caffeine ingestion on resistance exercise performance. J Strength Cond Res. 2016;30(10):2892-900.

165. Trexler ET, Smith-Ryan AE, Roelofs EJ, Hirsch KR, Mock MG. Effects of coffee and caffeine anhydrous on strength and sprint performance. Eur J Sport Sci. 2016;16(6):702-10. 
166. Desbrow B, Hall S, Irwin C. Caffeine content of Nespresso ${ }^{\circledR}$ pod coffee. Nutr Health. 2018. https://doi.org/10.1177/0260106018 810941 .

167. Desbrow B, Hall S, O'Connor H, Slater G, Barnes K, Grant G. Caffeine content of pre-workout supplements commonly used by Australian consumers. Drug Test Anal. 2018. https://doi. org/10.1002/dta.2501.

168. Mündel T, King J, Collacott E, Jones DA. Drink temperature influences fluid intake and endurance capacity in men during exercise in a hot, dry environment. Exp Physiol. 2006;91(5):925-33.

169. Pasman WJ, van Baak MA, Jeukendrup AE, de Haan A. The effect of different dosages of caffeine on endurance performance time. Int J Sports Med. 1995;16(4):225-30.

170. Graham TE, Spriet LL. Metabolic, catecholamine, and exercise performance responses to various doses of caffeine. J Appl Physiol. 1995;78(3):867-74.

171. Desbrow B, Biddulph C, Devlin B, Grant GD, AnoopkumarDukie S, Leveritt MD. The effects of different doses of caffeine on endurance cycling time trial performance. J Sports Sci. 2012;30(2):115-20.

172. Astorino TA, Terzi MN, Roberson DW, Burnett TR. Effect of two doses of caffeine on muscular function during isokinetic exercise. Med Sci Sports Exerc. 2010;42(12):2205-10.

173. Pallarés JG, Fernández-Elías VE, Ortega JF, Muñoz G, MuñozGuerra J, Mora-Rodríguez R. Neuromuscular responses to incremental caffeine doses: performance and side effects. Med Sci Sports Exerc. 2013;45(11):2184-92.

174. Tallis J, Yavuz HC. The effects of low and moderate doses of caffeine supplementation on upper and lower body maximal voluntary concentric and eccentric muscle force. Appl Physiol Nutr Metab. 2017;43(3):274-81.

175. Langfort J, Dudohoski L, Dubaniewicz A, Challiss RA, Newsholme EA. Exercise-induced improvement in the sensitivity of the rat soleus muscle toinsulin is reversed by chloroadenosine - the adenosine receptor agonist. Biochem Med Metab Biol. 1993;50(1):18-23.

176. Cox GR, Desbrow B, Montgomery PG, Anderson ME, Bruce $\mathrm{CR}$, Macrides TA, et al. Effect of different protocols of caffeine intake on metabolism and endurance performance. J Appl Physiol. 2002;93(3):990-9.

177. Black CD, Waddell DE, Gonglach AR. Caffeine's ergogenic effects on cycling: neuromuscular and perceptual factors. Med Sci Sports Exerc. 2015;47(6):1145-58.

178. Jenkins NT, Trilk JL, Singhal A, O’Connor PJ, Cureton KJ. Ergogenic effects of low doses of caffeine on cycling performance. Int J Sport Nutr Exerc Metab. 2008;18(3):328-42.

179. Glaister M, Patterson SD, Foley P, Pedlar CR, Pattison JR, McInnes G. Caffeine and sprinting performance: dose responses and efficacy. J Strength Cond Res. 2012;26(4):1001-5.

180. Trevino MA, Coburn JW, Brown LE, Judelson DA, Malek MH. Acute effects of caffeine on strength and muscle activation of the elbow flexors. J Strength Cond Res. 2015;29(2):513-20.

181. Scott AT, O'Leary T, Walker S, Owen R. Improvement of 2000-m rowing performance with caffeinated carbohydrate-gel ingestion. Int J Sports Physiol Perform. 2015;10(4):464-8.

182. Duncan MJ, Clarke ND, Tallis J, Guimaraes-Ferreira L, Wright SL. The effect of caffeine ingestion on functional performance in older adults. J Nutr Health Aging. 2014;18(10):883-7.

183. Swift CG, Tiplady B. The effects of age on the response to caffeine. Psychopharmacology. 1988;94(1):29-31.

184. Tallis J, James RS, Cox VM, Duncan MJ. Is the ergogenicity of caffeine affected by increasing age? The direct effect of a physiological concentration of caffeine on the power output of maximally stimulated EDL and diaphragm muscle isolated from the mouse. J Nutr Health Aging. 2017;21(4):440-8.
185. Ilich JZ, Brownbill RA, Tamborini L, Crncevic-Orlic Z. To drink or not to drink: how are alcohol, caffeine and past smoking related to bone mineral density in elderly women? J Am Coll Nutr. 2002;21(6):536-44.

186. Hallström H, Melhus H, Glynn A, Lind L, Syvänen AC, Michaëlsson K. Coffee consumption and CYP1A2 genotype in relation to bone mineral density of the proximal femur in elderly men and women: a cohort study. Nutr Metab. 2010;7(1):12.

187. Nurminen ML, Niittynen L, Korpela R, Vapaatalo H. Coffee, caffeine and blood pressure: a critical review. Eur J Clin Nutr. 1999;53(11):831.

188. Geleijnse JM. Habitual coffee consumption and blood pressure: an epidemiological perspective. Vasc Health Risk Manag. 2008;4(5):963-70.

189. Johnson-Kozlow M, Kritz-Silverstein D, Barrett-Connor E, Morton D. Coffee consumption and cognitive function among older adults. Am J Epidemiol. 2002;156(9):842-50.

190. O'Keefe JH, Bhatti SK, Patil HR, DiNicolantonio JJ, Lucan SC, Lavie CJ. Effects of habitual coffee consumption on cardiometabolic disease, cardiovascular health, and all-cause mortality. J Am Coll Cardiol. 2013;62(12):1043-51.

191. Grgic J, Grgic I, Pickering C, Schoenfeld B, Bishop D, Pedisic Z. Wake up and smell the coffee: caffeine supplementation and exercise performance - an umbrella review of 21 published metaanalyses. Br J Sports Med. 2019;. https://doi.org/10.1136/bjspo rts-2018-100278.

192. Baker LB, Rollo I, Stein KW, Jeukendrup AE. Acute effects of carbohydrate supplementation on intermittent sports performance. Nutrients. 2015;7(7):5733-63.

193. Waldron M, Patterson SD, Tallent J, Jeffries O. The effects of an oral taurine dose and supplementation period on endurance exercise performance in humans: a meta-analysis. Sports Med. 2018;48(5):1247-53.

194. Shabir A, Hooton A, Tallis J, F Higgins M. The influence of caffeine expectancies on sport, exercise, and cognitive performance. Nutrients. 2018;10(10):1528.

195. Saunders B, de Oliveira LF, da Silva RP, de Salles Painelli V, Gonçalves LS, Yamaguchi G, et al. Placebo in sports nutrition: a proof-of-principle study involving caffeine supplementation. Scand J Med Sci Sports. 201727(11):1240-7.

196. Del Coso J, Pérez-López A, Abian-Vicen J, Salinero JJ, Lara B, Valadés D. Enhancing physical performance in male volleyball players with a caffeine-containing energy drink. Int J Sports Physiol Perform. 2014;9(6):1013-8.

197. Del Coso J, Ramírez JA, Muñoz G, Portillo J, Gonzalez-Millán $\mathrm{C}$, Muñoz V, et al. Caffeine-containing energy drink improves physical performance of elite rugby players during a simulated match. Appl Physiol Nutr Metab. 2012;38(4):368-74.

198. Del Coso J, Muñoz-Fernández VE, Muñoz G, Fernández-Elías VE, Ortega JF, Hamouti N, et al. Effects of a caffeine-containing energy drink on simulated soccer performance. PLoS One. 2012;7(2):e31380.

199. Lara B, Gonzalez-Millán C, Salinero JJ, Abian-Vicen J, Areces $\mathrm{F}$, Barbero-Alvarez JC, et al. Caffeine-containing energy drink improves physical performance in female soccer players. Amino Acids. 2014;46(5):1385-92.

200. Abian-Vicen J, Puente C, Salinero JJ, González-Millán C, Areces F, Muñoz G, et al. A caffeinated energy drink improves jump performance in adolescent basketball players. Amino Acids. 2014;46(5):1333-41.

201. Lara B, Ruiz-Vicente D, Areces F, Abián-Vicén J, Salinero JJ, Gonzalez-Millán C, et al. Acute consumption of a caffeinated energy drink enhances aspects of performance in sprint swimmers. Br J Nutr. 2015;114(6):908-14. 
202. Miller LS, Lombardo TW, Fowler SC. Caffeine and time of day effects on a force discrimination task in humans. Physiol Behav. 1995;57(6):1117-25.

203. Evans M, Tierney P, Gray N, Hawe G, Macken M, Egan B. Acute ingestion of caffeinated chewing gum improves repeated sprint performance of team sport athletes with low habitual caffeine consumption. Int J Sport Nutr Exerc Metab. 2018;28(3):221-7.

204. Jordan BJ, Farley RS, Caputo JL. Caffeine and sprint performance in habitual and caffeine naïve participants. Int J Exerc Sci. 2012;5(1):50-9.

205. Tarnopolsky M, Cupido C. Caffeine potentiates low frequency skeletal muscle force in habitual and nonhabitual caffeine consumers. J Appl Physiol. 2000;89(5):1719-24.

206. Wiles JD, Bird SR, Hopkins J, et al. Effect of caffeinated coffee on running speed, respiratory factors, blood lactate and perceived exertion during 1500-m treadmill running. Br J Sports Med. 1992;26(2):116-20.

207. Arazi H, Hoseinihaji M, Eghbali E. The effects of different doses of caffeine on performance, rating of perceived exertion and pain perception in teenagers female karate athletes. Braz J Pharm Sci. 2016;52(4):685-92.

208. Bruce CR, Anderson ME, Fraser SF, Stepto NK, Klein R, Hopkins WG, et al. Enhancement of 2000-m rowing performance after caffeine ingestion. Med Sci Sports Exerc. 2000;32(11):1958-63.

209. Bugyi GJ. The effects of moderate doses of caffeine on fatigue parameters of the forearm flexor muscles. Am Correct Ther J. 1980;34(2):49-53.

210. Cohen BS, Nelson AG, Prevost MC, Thompson GD, Marx $\mathrm{BD}$, Morris GS. Effects of caffeine ingestion on endurance racing in heat and humidity. Eur J Appl Physiol Occup Physiol. 1996;73(3-4):358-63.

211. Del Coso J, Salinero JJ, González-Millán C, Abián-Vicén J, Pérez-González B. Dose response effects of a caffeine-containing energy drink on muscle performance: a repeated measures design. J Int Soc Sports Nutr. 2012;9(1):21.
212. Desbrow B, Barrett CM, Minahan CL, Grant GD, Leveritt MD. Caffeine, cycling performance, and exogenous $\mathrm{CHO}$ oxidation: a dose-response study. Med Sci Sports Exerc. 2009;41(9):1744-51.

213. Ellis M, Noon M, Myers T, Clarke N. Low doses of caffeine: enhancement of physical performance in elite adolescent male soccer players. Int J Sports Physiol Perform. 2018. https://doi. org/10.1123/ijspp.2018-0536.

214. Jacobson BH, Edwards SW. Influence of two levels of caffeine on maximal torque at selected angular velocities. J Sports Med Phys Fitness. 1991;31(2):147-53.

215. Kovacs EM, Stegen JHCH, Brouns F. Effect of caffeinated drinks on substrate metabolism, caffeine excretion, and performance. J Appl Physiol (1985). 1998;85(2):709-15.

216. McLellan TM, Bell DG. The impact of prior coffee consumption on the subsequent ergogenic effect of anhydrous caffeine. Int J Sport Nutr Exerc Metab. 2004;14(6):698-708.

217. McNaughton LR. The influence of caffeine ingestion on incremental treadmill running. Br J Sports Med. 1986;20(3):109-12.

218. Perkins R, Williams MH. Effect of caffeine upon maximal muscular endurance of females. Med Sci Sports. 1975;7(3):221-4.

219. Skinner TL, Jenkins DG, Coombes JS, Taaffe DR, Leveritt MD. Dose response of caffeine on 2000-m rowing performance. Med Sci Sports Exerc. 2010;42(3):571-6.

220. Stadheim HK, Kvamme B, Olsen R, Drevon CA, Ivy JL, Jensen $\mathrm{J}$. Caffeine increases performance in cross-country double-poling time trial exercise. Med Sci Sports Exerc. 2013;45(11):2175-83.

221. Turley K, Eusse PA, Thomas MM, Townsend JR, Morton AB. Effects of different doses of caffeine on anaerobic exercise in boys. Pediatr Exerc Sci. 2015;27(1):50-6. 